Chemical Technology

ANL-02/31

Division

Chemical Technology

Division

Chemical Technology

Division

Chemical Technology

Division

Chemical Technology

Division

Chemical Technology

Division

Chemical Technology

Division

Chemical Technology

Division

Chemical Technology

Division

Chemical Technology

Division

Chemical Technology

Division

Chemical Technology

Division

Chemical Technology

Division

Chemical Technology

Division

Chemical Technology

Division

Chemical Technology

Division

Chemical Technology

Division

\author{
by H. A. Arafat, J. R. Falkenberg, \\ and R. A Leonard

\section{Solvent Recovery from Aqueous Effluent Using Process Diluent in the Caustic-Side Solvent \\ Extraction (CSSX) Process}

Argonne National Laboratory, Argonne, Illinois 60439

operated by The University of Chicago

for the United States Department of Energy under Contract W-31-109-Eng-38

Chemical Technology

Division

Chemical Technology

Division

Chemical Technology

Division

Chemical Technology

Division 
Argonne National Laboratory, with facilities in the states of Illinois and Idaho, is owned by the United States Government and operated by The University of Chicago under the provisions of a contract with the Department of Energy.

\begin{tabular}{l} 
DISCLAIMER \\
This report was prepared as an account of work sponsored by an agency of \\
the United States Government. Neither the United States Government nor \\
any agency thereof, nor The University of Chicago, nor any of their \\
employees or officers, makes any warranty, express or implied, or assumes \\
any legal liability or responsibility for the accuracy, completeness, or \\
usefulness of any information, apparatus, product, or process disclosed, or \\
represents that its use would not infringe privately owned rights. Reference \\
herein to any specific commercial product, process, or service by trade name, \\
trademark, manufacturer, or otherwise, does not necessarily constitute or \\
imply its endorsement, recommendation, or favoring by the United States \\
Government or any agency thereof. The views and opinions of document \\
authors expressed herein do not necessarily state or reflect those of the \\
United States Government or any agency thereof, Argonne National \\
Laboratory, or The University of Chicago. \\
\hline
\end{tabular}

Available electronically at http://www.doe.gov/bridge

Available for a processing fee to U.S. Department of Energy and its contractors, in paper, from:

U.S. Department of Energy

Office of Scientific and Technical Information

P.O. Box 62

Oak Ridge, TN 37831-0062

phone: (865) 576-8401

fax: (865) 576-5728

email: reports@adonis.osti.gov 
ANL-02/31

\section{SOLVENT RECOVERY FROM AQUEOUS EFFLUENT USING PROCESS DILUENT IN THE CAUSTIC-SIDE SOLVENT EXTRACTION (CSSX) PROCESS}

H. A. Arafat, J. R. Falkenberg, and R. A. Leonard

February 20, 2002 


\section{CONTENTS}

ABSTRACT $\quad \underline{\text { Page }}$

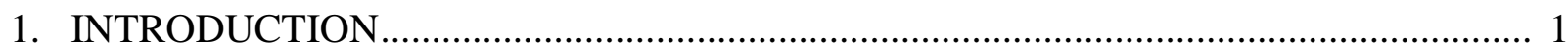

2. SUMMARY AND CONCLUSIONS ...................................................................... 3

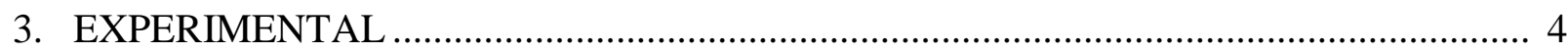

3.1 Solvent Recovery Using Diluent Contact ..................................................... 4

3.2 Diluent Concentration Using Vacuum Distillation ............................................ 6

4. THEORY AND MODELING ............................................................................. 7

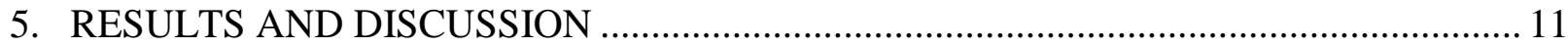

5.1 Solvent Recovery Using Diluent Contact ....................................................... 11

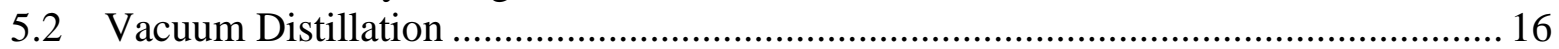

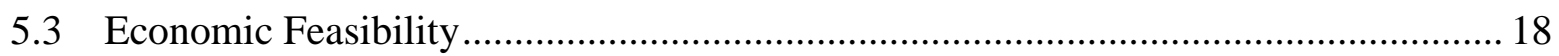

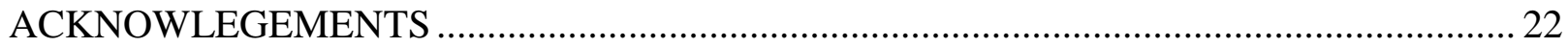

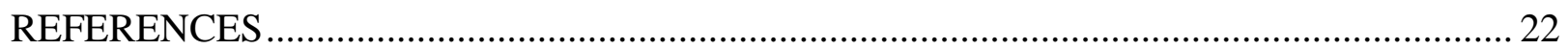

APPENDIX A: HYDRAULIC TESTS PERFORMED TO CHECK 4-CM CONTACTORS USED DURING SOLVENT RECOVERY TEST ..................................... 25

APPENDIX B: CALCULATIONS OF SOLVENT ENTRAINMENT DURING SOLVENT RECOVERY TEST

APPENDIX C: CALCULATIONS FOR SOLVENT RECOVERY USING A DECANTER TANK

APPENDIX D: CALCULATIONS FOR SOLVENT RECOVERY USING A CENTRIFUGE

APPENDIX E: CALCULATIONS FOR SOLVENT RECOVERY USING DILUENT CONTACT IN CENTRIFUGAL CONTACTOR 


\section{FIGURES}

1. Flowsheet for CSSX Process Proof-of-Concept Test with Solvent Recycle .................... 2

2. Flowsheet for Test of Solvent Recovery Using Diluent Contact ............................... 5

3. Schematic of Vacuum Distillation Apparatus ...................................................... 7

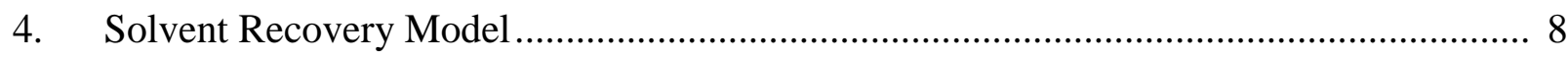

5. Average and Standard Deviation for Model Prediction Accuracy................................ 14

6. Effects of Organic Entrainment and Stage Efficiency on BOBCalixC6 in First and Second Diluent Reservoirs ................................................................................ 15

7. Effects of Organic Entrainment and Stage Efficiency on Annual Cost of Unrecovered Solvent in 2-Stage Diluent-Contact Unit for Solvent Recovery ................................... 20

8. Effect of Diluent Volume in Diluent-Contact Stages on Annual Cost of Unrecovered Solvent in 2-Stage Diluent-Contact Unit for Solvent Recovery at

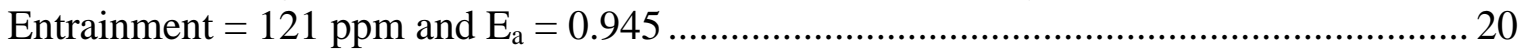

B-1. Material Balance Calculations for Solvent Entrainment .......................................... 27

C-1. Solvent Recovery in Decanter Tank..................................................................... 31 


\section{TABLES}

1. Partitioning Concentrations for CSSX Solvent Components in Key Aqueous

2. Liquid Appearance During Solvent Recovery Test ............................................... 11

3. Changes in Liquid Volume During Solvent Recovery Test....................................... 11

4. BOBCalixC6 and Modifier Concentrations During Solvent Recovery Test ................... 13

5. Model Sample Calculation Using $\mathrm{E}_{\mathrm{a}}=0.97, \mathrm{Co}=0.01 \underline{\mathrm{M}}$, and $\mathrm{C}_{\mathrm{T} 1,0}=0 \ldots \ldots \ldots \ldots \ldots \ldots \ldots \ldots . . . \ldots \ldots$

6. Concentration of BOBCalixC6 and Modifier in Concentrated and Condensed Diluent.

7. Comparison of Solvent Recovery Options .......................................................... 21

A-1. Zero-Point Test Results for 4-cm Contactors Used in Solvent Recovery Tests

A-2. Single-Stage, Two-Phase Test Results for 4-cm Contactors Used in Solvent Recovery Tests

E-1. Moles of BOBCalixC6 Not Recovered by Diluent Contact

E-2. Moles of Modifier Not Recovered by Diluent Contact 38 


\title{
SOLVENT RECOVERY FROM AQUEOUS EFFLUENT USING PROCESS DILUENT IN THE CAUSTIC-SIDE SOLVENT EXTRACTION (CSSX) PROCESS
}

\author{
H. A. Arafat, J. R. Falkenberg, and R. A. Leonard
}

February 20, 2002

\begin{abstract}
In this work, solvent recovery from aqueous CSSX process raffinate effluent was tested using the process diluent (Isopar ${ }^{\circledR} \mathrm{L}$ ). A model was developed to obtain stage efficiency for the diluent contact stages. The model was used to fit experimental data from a 19.8-hr solvent recovery test. Diluent-in-aqueous entrainment was measured during the test. Vacuum distillation was used to concentrate the solvent components, BOBCalixC6 and modifier, in the diluent used in solvent recovery. Using the results, a feasibility study was performed to compare the annual cost of lost solvent under each of four solvent recovery options. These options were decanter tank, centrifuge, two-stage diluent contact using centrifugal contactor, and no solvent recovery action.
\end{abstract}

\section{INTRODUCTION}

About 34 million gallons of high-level radioactive waste are currently stored in underground tanks at the Savannah River Site (SRS) near Aiken, South Carolina [LEVENSON2000]. Recently, a process developed at Oak Ridge National Laboratory (ORNL), in collaboration with Argonne National Laboratory (ANL) and SRS, was selected to remove cesium-137 $\left({ }^{137} \mathrm{Cs}\right)$ from the waste prior to immobilizing the waste in low-level grout. The treatment technology, which is a caustic-side solvent extraction (CSSX) process, will utilize a multistage centrifugal contactor to extract ${ }^{137} \mathrm{Cs}$ from the waste [LEONARD-2000]. The solvent used in this process consists of four components: (1) an extractant-calix[4]arene-bis(tertoctylbenzo-crown-6), designated BOBCalixC6, which is a calixarene crown that is very specific for cesium extraction; (2) a modifier-1-(2,2,3,3,-tetrafluoropropoxy)-3-(4-sec-butylphenoxy)-2propanol, also called Cs-7SB, which is an alkyl aryl polyether that keeps the extractant dissolved in the solvent and increases its ability to extract cesium in the extraction section; (3) a suppressant - trioctylamine (TOA), which suppresses effects of organic impurities to ensure that the cesium can be back-extracted from the solvent in the strip section; and (4) a diluentIsopar ${ }^{\circledR} \mathrm{L}$, which is a mixture of branched-chain hydrocarbons. The original baseline solvent composition was $0.01 \underline{\mathrm{M}}$ BOBCalixC6, 0.5 $\underline{\mathrm{M}} \mathrm{Cs}-7 \mathrm{SB}$, and $0.001 \underline{\mathrm{M}}$ TOA in Isopar ${ }^{\circledR} \mathrm{L}$ and is designated the "CSSX solvent." It is worth mentioning that the CSSX solvent has been recently optimized to overcome certain technical issues related to the original solvent composition. The new (optimized) solvent composition is $0.007 \underline{\mathrm{M}}$ BOBCalixC6, $0.75 \underline{\mathrm{M}} \mathrm{Cs}-7 \mathrm{SB}$, and $0.003 \underline{\mathrm{M}}$ TOA in Isopar ${ }^{\circledR}$ L. Since the work reported here was initiated before optimizing the solvent composition, the discussion in this document is based on the original solvent composition. The 
flowsheet for the CSSX process proof-of-concept test, performed at ANL in FY00, is shown in Figure 1 [LEONARD-2000]. In the extraction section (stages 1 through 15 in Figure 1), cesium is extracted from the alkaline waste feed by the CSSX solvent. Then, as the organic solvent flows through the scrub section (stages 16 and 17), entrained alkaline aqueous solution and weakly extracted potassium are removed from the solvent. In the strip section (stages 18 through 32), cesium is stripped from the CSSX solvent into dilute nitric acid.

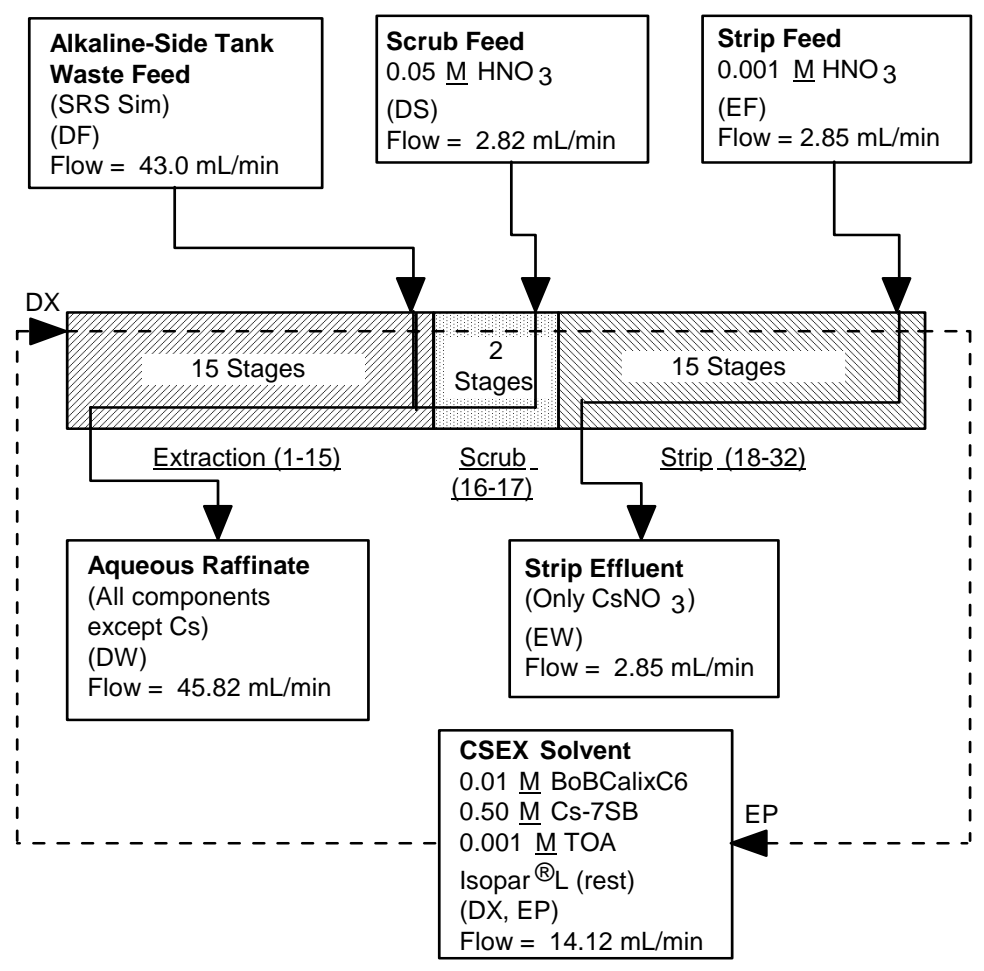

Figure 1. Flowsheet for CSSX Process Proof-of-Concept Test with Solvent Recycle

Because the cost of the CSSX solvent is high, information is needed on how much solvent is lost in the process. If enough solvent is lost in the aqueous effluents, the overall cost of the CSSX process can increase significantly. According to recent estimates, the costs for BOBCalixC6, Cs-7SB, and Isopar® $\mathrm{L}$ are $\$ 150 / \mathrm{g}, \$ 1.5 / \mathrm{g}$, and $\$ 5 / \mathrm{gal}$, respectively [BONNESEN-2001, LEONARD-2001]. Based on these estimates, the cost of baseline solvent is about $\$ 1900 / \mathrm{L}$. Of this cost, $87 \%$ is attributed to BOBCalixC6 and $13 \%$ is attributed to Cs-7SB. During the CSSX process, solvent loss to the aqueous phase occurs via two mechanisms: partitioning (dissolution) and entrainment. Solvent loss through partitioning is dependent on the distribution ratios (i.e., D values) of the solvent components between the organic and aqueous phases. D values for the CSSX solvent components with the aqueous phases for the extraction and strip sections were measured by ORNL [MOYER-2001]. The results, given in Table 1, show that the partitioning concentrations for the modifier in the aqueous phase are 8 to 30 times higher than those for the BOBCalixC6. This is not unexpected since the modifier concentration in the solvent is 50 times higher than that for the BOBCalixC6. 


\section{Table 1. Partitioning Concentrations for CSSX Solvent Components in Key Aqueous Phases of CSSX Process}

\begin{tabular}{|l|c|c|c|}
\hline \multirow{2}{*}{$\begin{array}{c}\text { Section for } \\
\text { Aqueous } \\
\text { Solution }\end{array}$} & \multicolumn{3}{|c|}{ CSSX Solvent Component } \\
\cline { 2 - 4 } & BOBCalixC6 (M) & Modifier (M) & Isopar $^{\circledR}$ L (M) \\
\hline Strip & $8.90 \mathrm{E}-07$ & $7.41 \mathrm{E}-05$ & $1.00 \mathrm{E}-07$ \\
\hline Extraction & $3.30 \mathrm{E}-08$ & Less than 1E-5 & Less than 6E-07 \\
\hline
\end{tabular}

(a) Based on solubility in water at $0.001 \%$ and an average molecular weight of $171 \mathrm{~g} / \mathrm{mol}$ [EXXON-2000].

A number of options were considered for solvent recovery. Physical separations using decanters, centrifuges, and coalescers were discussed in earlier work, where a solvent decanter was tested [ARAFAT-2001]. In this work, chemical separation is studied by contacting the aqueous phase with organic diluent, Isopar ${ }^{\circledR}$ L. This is the diluent used in the CSSX solvent. By using it for solvent recovery, the need for separating the recovered solvent components from the diluent is eliminated. The diluent with the recovered extractant and modifier can be either (1) used directly as a CSSX solvent by adding more of the solvent components to achieve the concentrations of the fresh CSSX solvent, or (2) concentrated by vacuum distillation to increase the component concentrations to the level of the CSSX solvent. Although current knowledge of process chemistry indicates that Isopar $^{\circledR} \mathrm{L}$ should be able to capture the entrained solvent components, the experimental work was performed to demonstrate this concept. Also, experimental results were needed to determine the stage efficiency that could be achieved using such a process. Previous experience at ANL with the centrifugal contactors indicates that stage efficiencies should be high.

\section{SUMMARY AND CONCLUSIONS}

Recovery of dissolved solvent is not economically justified. However, the high cost of solvent lost by entrainment suggests that its recovery should lead to significant process savings. As discussed in a previous report [ARAFAT-2001], solvent entrainment accounts for most (more than $85 \%$ ) of the solvent lost in the extraction section. Solvent entrainment was found to average $121 \mathrm{ppm}$ when no process upsets, which cause significant other-phase carryover, occur. At this level of entrainment (121 ppm) and based on a 20.1-gal/min plant-scale operation [HODGES2000] for 240-days per year, the total annual cost of solvent lost via entrainment to both extraction and strip solutions would be $\$ 6,850,000$. For the same plant, the total annual cost of BOBCalixC6 and modifier lost via partitioning is $\$ 633,000$, which is only $9 \%$ the cost of entrained solvent.

Diluent contact can be used for solvent recovery. Two 4-cm centrifugal contactor stages were used with the process diluent, Isopar ${ }^{\circledR} \mathrm{L}$ to test solvent recovery from the aqueous waste raffinate. The total test duration was 19.8 hours. A model was developed based on the material balance and the efficiency of the two diluent contact stages. Experimental data from the test, 
including concentrations and volume changes, were used to fit the model. The stage efficiency was found to be about 94\%. The observed amounts of entrainment in the aqueous flow exiting the two diluent contact stages were more than $121 \mathrm{ppm}(0.012 \%)$. However, these amounts are well within the limits of acceptable entrainment limit for a process without hydraulic performance upsets, which is $<1 \%$.

Post-diluent-contact treatment options are concentration by evaporation or direct use after concentration make-up. Vacuum distillation was tested as a method for concentrating the solvent components (BOBCalixC6 and modifier) in the diluent used in the solvent recovery process. A high temperature of $135{ }^{\circ} \mathrm{C}$ was needed to evaporate the diluent at a vacuum of $29.5 \mathrm{in} . \mathrm{Hg}$. Using vacuum distillation to evaporate the excess diluent, we were able to increase the concentrations of both BOBCalixC6 and modifier up to that of fresh CSSX solvent. Poor material balance and analytical data add significant uncertainty to the numerical values cited.

An economic feasibility study was performed to compare four solvent recovery options using the annual cost of lost solvent as the sole criterion. The four solvent recovery options are decanter tank, diluent contact in centrifugal contactor, centrifuge, and no recovery action. We concluded that diluent contact in the centrifugal contactor achieves the lowest lost-solvent cost; however, the organic entrainment in the aqueous phase after being contacted with diluent for solvent recovery indicates the need for a post-recovery coalescer or centrifuge to recover any high entrainments. Therefore, the use of a coalescer or a centrifuge for solvent recovery may be attractive, as it would be simpler to implement and would make the process simpler to operate. It has yet to be experimentally tested and there are technical issues to be explored. The feasibility study did not discuss the use of coalescer, due to lack of experimental data on this technique. Only diluent contact can recover the partitioned solvent components. However, as this contribution to solvent loss is small, diluent contact may not be needed if the centrifuge or coalescer can remove most of the entrained solvent.

\section{EXPERIMENTAL}

The experimental work was done to demonstrate (1) solvent recovery by diluent contact and (2) the concentration of solvent components in the diluent using vacuum distillation. In both types of experiments, data were obtained by analyzing diluent samples, collected throughout the tests, for BOBCalixC6 and Cs-7SB concentrations. The samples were sent to ORNL for chemical analysis; all conclusions were dependent on the accuracy of those measurements. The experimental techniques for measuring the concentrations at ORNL were subject to review and modifications. The margin of experimental error reported by ORNL for these techniques is up to $\pm 20 \%$ [MOYER-2001].

\subsection{Solvent Recovery Using Diluent Contact}

A three-stage 4-cm centrifugal contactor was used to study solvent recovery from aqueous waste raffinate by diluent contact. The $4-\mathrm{cm}$ contactors were chosen because they have higher flow rates than the 2 -cm contactors. This should give a higher stage efficiency and more sample volume for analyses. The diluent-contact flowsheet is shown schematically in Figure 2. 


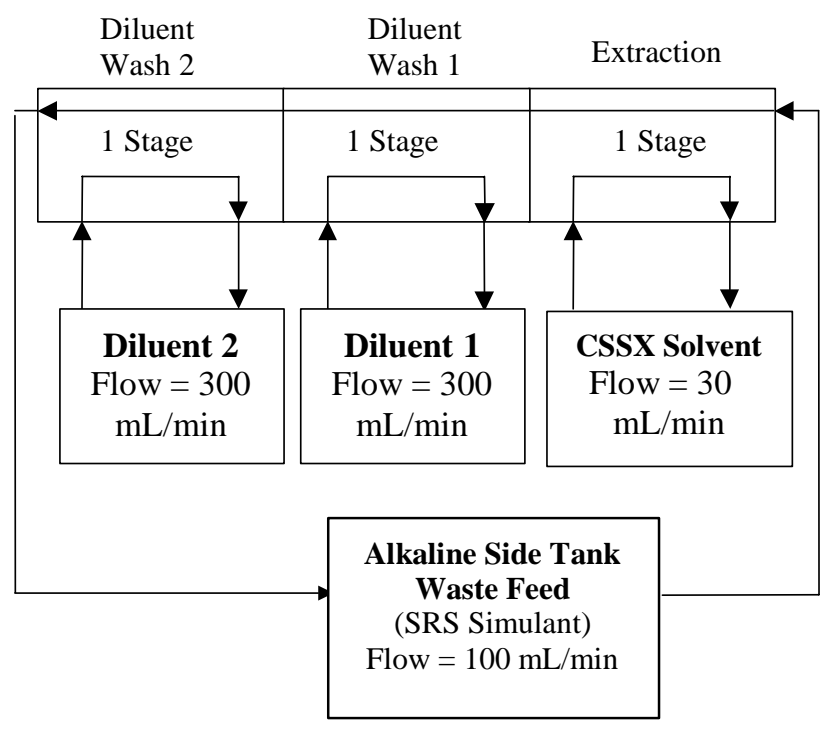

Figure 2. Flowsheet for Test of Solvent Recovery
Using Diluent Contact

In the first contactor stage (extraction stage), the aqueous waste simulant was contacted, at a flow rate of $100 \mathrm{~mL} / \mathrm{min}$, with the CSSX solvent to induce entrainment of the solvent in the aqueous phase. In this stage, we created the organic entrainment that occurs in the extractionsection aqueous phase. The organic/aqueous $(\mathrm{O} / \mathrm{A})$ ratio, 0.3 , is similar to that in the extraction section of the CSSX process flowsheet. Next, the aqueous phase, with CSSX solvent entrained within it, was contacted with the diluent, Isopar ${ }^{\circledR} \mathrm{L}$, in the second and third stages (herein referred to as the first and second diluent contact stages, respectively). As the diluent mixes with the aqueous phase, it combines with the solvent components of the entrained solvent, reducing the concentration of these components in the entrained solvent droplets and increasing it in the diluent. It also partitions the solvent components dissolved in the aqueous phase and reduces their concentrations. As the diluent was recycled, the concentration of solvent components increased in the diluent. The third stage (the second diluent-contact stage) served as a backup to recover solvent components that were not recovered in the first diluent contact stage. The O/A ratio in both diluent contact stages was 3 . At a high O/A flow ratio, the stages should operate under organic-continuous mode, which should limit the amount of solvent entrained in the aqueous effluent. As the aqueous effluent left the third stage, it was recycled to a container from which it was continuously pumped into the extraction stage. The solutions were recycled for a total of 19.8 hours over a five-day period. The test was started with 1,000,300, 200, and $200 \mathrm{~mL}$ of the simulant, solvent, first diluent, and second diluent, respectively. At intervals and at the end of the test, samples from solvent and first and second diluent containers were collected and sent to ORNL for component analysis. ORNL used its standard analytical procedures to measure these concentrations [MASKARINEC-2001]. 
Prior to starting the solvent recovery test, we checked all three stages for run-out and spin-down time using the procedure described in LEONARD-2001. Rotor run-outs were found to be equal to or less than 0.011 inches. Spin-down tests indicated that the rotors were spinning freely inside the stages without mechanical hindrance. Hydraulic-performance tests were also performed to verify that the hydraulic performance of the contactors was acceptable. Two types of tests were performed: zero-point tests and single-stage two-phase tests, as described in LEONARD-2001. Results from the zero-point and the single-stage two-phase tests are given in Appendix A.

Zero-point tests indicate that the $4-\mathrm{cm}$ contactor is capable of handling $100 \mathrm{~mL} / \mathrm{min}$ of aqueous flow without the risk of aqueous-in-organic carryover. The two-phase test results indicate that the 4-cm contactor is capable of processing a total flow rate of $130 \mathrm{~mL}$ in the extraction stage $(\mathrm{O} / \mathrm{A}=0.3)$ and a total flow rate of $400 \mathrm{~mL} / \mathrm{min}$ in the two diluent contact stages $(\mathrm{O} / \mathrm{A}=3)$ without unacceptable other-phase carryover. For normal contactor operation, otherphase carryover becomes unacceptable whenever either phase has $>1 \%$ of the other phase entrained in it. Entrainment at levels $<1 \%$ can be acceptable for contactor operation but unacceptable in terms of solvent loss.

\subsection{Diluent Concentration Using Vacuum Distillation}

Vacuum distillation tests were performed to assess the ability of the process to concentrate the two key solvent components, BOBCalixC6 and the modifier, in the diluent used for solvent recovery. This is achieved by evaporating the excess diluent, which causes the concentration of the less volatile solvent components to increase in the residual diluent. The vacuum distillation apparatus ( ROTAVAPOR, Model RE-120, Buchi Instruments, Schweiz, Switzerland) is shown schematically in Figure 3. The test was started by placing an accurately weighed diluent sample to be concentrated in the 50-mL "concentrate" bulb. This was followed by heating the oil bath to the desired temperature and adjusting the pressure inside the evaporator using the vacuum pump. The concentrate bulb was then lowered slowly into the oil bath while rotating around its axis. The rotational motion coats the internal bulb walls with a layer of diluent, which facilitates its evaporation. As the diluent evaporates, the vapor moves upward through the "transfer tube" to the "condenser" chamber. The vapor is cooled in the condenser using cooling water at $3{ }^{\circ} \mathrm{C}$. As the diluent condenses, its droplets accumulate in the "condensate" bulb. After running the test for about 15 minutes, diluent evaporation ceased, the vacuum was released, and the remaining diluent in the concentrate bulb was weighed. Two samples were then taken from the concentrate and condensate liquids for component analysis. 


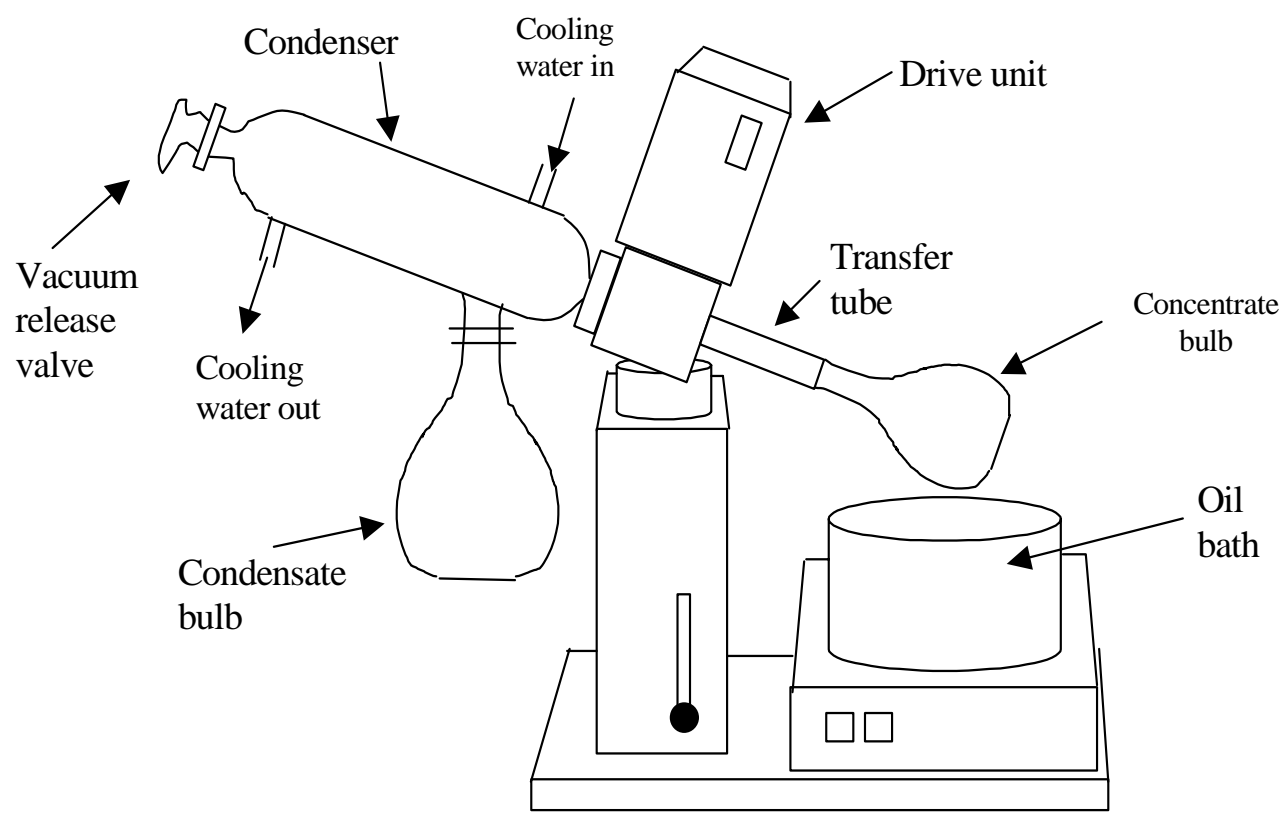

Figure 3. Schematic of Vacuum Distillation Apparatus

\section{THEORY AND MODELING}

Stage efficiency values are needed to predict the performance of the diluent contact stages in plant-scale operation. In order to calculate stage efficiency from experimental data, we developed a model based on material balance correlations for BOBCalixC6. In doing the material balance calculations for the extractant, the dissolved (partitioned) BOBCalixC6 was assumed to be negligible when compared with the entrained amount. This assumption is supported by the high D value for BOBCalixC6 in the extraction section, which can be calculated from Table 1. In the model, each diluent contact stage, along with its diluent container, was simulated by a mixed tank, as shown in Figure 4. 


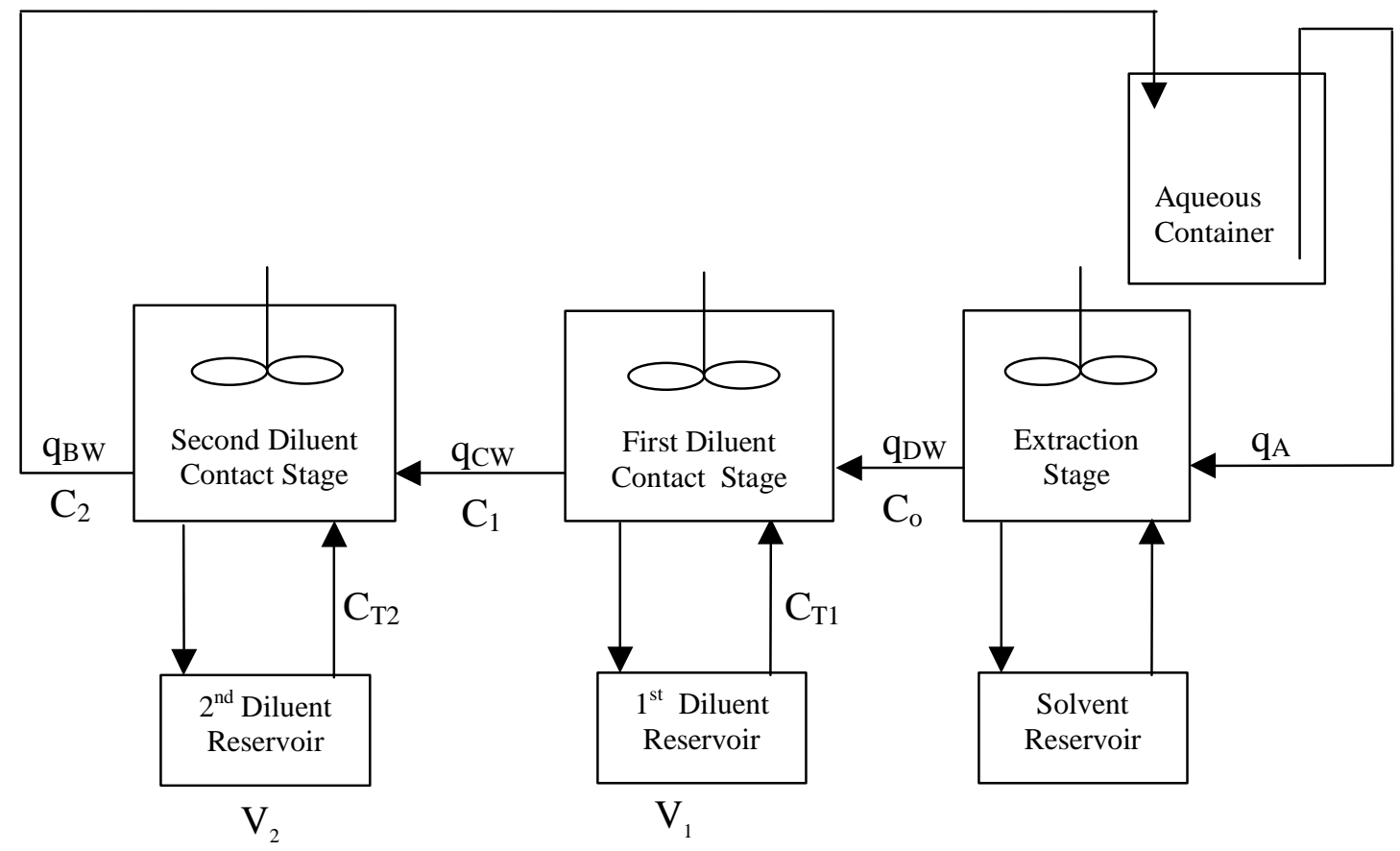

Figure 4. Solvent Recovery Model

Following are definitions for the symbols used in Figure 4:

$\mathrm{q}_{\mathrm{A}}$ : Volume flow rate of organic entrained in aqueous phase entering the extraction stage (L/min)

qDw: Volume flow rate of organic entrained in aqueous phase entering the first diluent contact stage (L/min)

qCw: Volume flow rate of organic entrained in aqueous phase entering the second diluent contact stage (L/min)

qBw: Volume flow rate of organic entrained in aqueous phase exiting the second diluent contact stage $(\mathrm{L} / \mathrm{min})$

$\mathrm{C}_{\mathrm{o}}$ : Concentration of BOBCalixC6 in the solvent entrained in $\mathrm{q}_{\mathrm{DW}}(\underline{\mathrm{M}})$

$\mathrm{C}_{1}$ : Concentration of BOBCalixC6 in the diluent entrained in $\mathrm{q}_{\mathrm{CW}}(\underline{\mathrm{M}})$

$\mathrm{C}_{2}$ : $\quad$ Concentration of BOBCalixC6 in the diluent entrained in $\mathrm{q}_{\mathrm{BW}}(\underline{\mathrm{M}})$

$\mathrm{V}_{1}$ : Liquid volume in first diluent reservoir (L)

$\mathrm{V}_{2}$ : $\quad$ Liquid volume in second diluent reservoir (L)

$\mathrm{C}_{\mathrm{T} 1}$ : Concentration of BOBCalixC6 in first diluent reservoir $(\underline{\mathrm{M}})$

$\mathrm{C}_{\mathrm{T} 2}$ : Concentration of BOBCalixC6 in second diluent reservoir $(\underline{\mathrm{M}})$

By definition of stage efficiency $\left(\mathrm{E}_{\mathrm{a}}\right)$ for the first diluent-contact stage,

$$
\mathrm{E}_{\mathrm{a}}=\frac{\mathrm{C}_{1}-\mathrm{C}_{\mathrm{o}}}{\mathrm{C}_{\mathrm{T} 1}-\mathrm{C}_{\mathrm{o}}}
$$


Then

$$
\mathrm{C}_{1}=\mathrm{E}_{\mathrm{a}} \mathrm{C}_{\mathrm{T} 1}+\left(1-\mathrm{E}_{\mathrm{a}}\right) \mathrm{C}_{\mathrm{o}} .
$$

Similarly, for the second diluent contact stage, and assuming the same stage efficiency for both stages,

$$
\mathrm{E}_{\mathrm{a}}=\frac{\mathrm{C}_{2}-\mathrm{C}_{1}}{\mathrm{C}_{\mathrm{T} 2}-\mathrm{C}_{1}}
$$

and

$$
\mathrm{C}_{2}=\mathrm{E}_{\mathrm{a}} \mathrm{C}_{\mathrm{T} 2}+\left(1-\mathrm{E}_{\mathrm{a}}\right) \mathrm{C}_{1} .
$$

By performing extractant material balance on the first diluent stage

$$
\mathrm{q}_{\mathrm{DW}} \mathrm{C}_{\mathrm{o}} \Delta \mathrm{t}=\mathrm{q}_{\mathrm{CW}} \mathrm{C}_{1} \Delta \mathrm{t}+\mathrm{V}_{1} \Delta \mathrm{C}_{\mathrm{T} 1} \text {, }
$$

where $\Delta \mathrm{C}_{\mathrm{T} 1}=\mathrm{C}_{\mathrm{T} 1, t 1}-\mathrm{C}_{\mathrm{T} 1, \text { to }}$, and $\mathrm{t}$ is time in minutes. Note that Equation 5 assumes a constant $\mathrm{V}_{1}$ value during the time interval. Substituting Equation 2 in Equation 5 to eliminate $C_{1}$ and setting $\Delta \mathrm{t} \rightarrow 0$,

$$
\frac{d \mathrm{C}_{\mathrm{T} 1}}{\left[\frac{\mathrm{q}_{\mathrm{DW}} \mathrm{C}_{\mathrm{o}}}{\mathrm{V}_{1}}-\frac{\left(1-\mathrm{E}_{\mathrm{a}}\right) \mathrm{q}_{\mathrm{CW}} \mathrm{C}_{\mathrm{o}}}{\mathrm{V}_{1}}\right]-\frac{\mathrm{E}_{\mathrm{a}} \mathrm{q}_{\mathrm{CW}} \mathrm{C}_{\mathrm{T} 1}}{\mathrm{~V}_{1}}}=d t
$$

Let

$$
\begin{gathered}
A=\frac{\mathrm{q}_{\mathrm{DW}} \mathrm{C}_{\mathrm{o}}}{\mathrm{V}_{1}}-\frac{\left(1-\mathrm{E}_{\mathrm{a}}\right) \mathrm{q}_{\mathrm{CW}} \mathrm{C}_{\mathrm{o}}}{\mathrm{V}_{1}} \\
\mathrm{~B}=\frac{\mathrm{E}_{\mathrm{a}} \mathrm{q}_{\mathrm{CW}}}{\mathrm{V}_{1}}
\end{gathered}
$$

Integrating,

$$
\mathrm{C}_{\mathrm{T} 1, \mathrm{t}}=\frac{\mathrm{A}}{\mathrm{B}}-\left[\frac{\mathrm{A}}{\mathrm{B}}-\mathrm{C}_{\mathrm{T} 1, \mathrm{o}}\right] \operatorname{Exp}[-\mathrm{Bt}],
$$

where

$\mathrm{C}_{\mathrm{T} 1, \mathrm{t}}: \quad$ BOBCalixC6 concentration in tank 1 at time $=\mathrm{t}(\underline{\mathrm{M}})$ and

$\mathrm{C}_{\mathrm{T} 1,0}$ : $\quad$ BOBCalixC6 concentration in tank 1 at time $=0(\underline{\mathrm{M}})$. 
Equation 9 indicates that, when $\mathrm{C}_{\mathrm{T} 1, \mathrm{o}}=0$ (as is the case during the solvent recovery test), then $\mathrm{C}_{\mathrm{T} 1, \mathrm{t}}$ will have a value equal to or greater than zero only when

$$
\mathrm{q}_{\mathrm{DW}} \geq(1-\mathrm{Ea}) \mathrm{q}_{\mathrm{CW}}
$$

The model has two special cases of interest. These are:

Case (1): when $\mathrm{C}_{\mathrm{T} 1, \mathrm{to}}=0, \mathrm{Ea}=100 \%$, and $\mathrm{q}_{\mathrm{DW}}=\mathrm{q}_{\mathrm{CW}}$

$$
\mathrm{C}_{\mathrm{T} 1, \mathrm{t}}=\mathrm{C}_{\mathrm{o}}\left[1-\operatorname{Exp}\left[-\frac{\mathrm{q}_{\mathrm{CW}}}{\mathrm{V}_{1}} t\right]\right]
$$

Case (2): when $\mathrm{C}_{\mathrm{T} 1, \mathrm{t}}=\mathrm{C}_{\mathrm{o}} / 2, \mathrm{C}_{\mathrm{T} 1, \mathrm{to}}=0, \mathrm{Ea}=100 \%$, and $\mathrm{q}_{\mathrm{DW}}=\mathrm{q}_{\mathrm{CW}}$

$$
1 / 2=1-\operatorname{Exp}\left[-\frac{\mathrm{q}_{\mathrm{CW}}}{\mathrm{V}_{1}} t\right]
$$

Similarly, by performing a material balance for BOBCalixC6 in the second diluent contact stage,

$$
\mathrm{q}_{\mathrm{CW}} \mathrm{C}_{1} \Delta \mathrm{t}=\mathrm{q}_{\mathrm{BW}} \mathrm{C}_{2} \Delta \mathrm{t}+\mathrm{V}_{2} \Delta \mathrm{C}_{\mathrm{T} 2}
$$

where

$\Delta \mathrm{C}_{\mathrm{T} 2}=\mathrm{C}_{\mathrm{T} 2, \mathrm{t} 1}-\mathrm{C}_{\mathrm{T} 2, \mathrm{to}}$,

$\mathrm{C}_{\mathrm{T} 2, \mathrm{to}}$ : BOBCalixC6 concentration in tank 2 at time $=\mathrm{t}(\underline{\mathrm{M}})$, and

$\mathrm{C}_{\mathrm{T} 2, \mathrm{t} 1}$ : $\mathrm{BOBCalixC6}$ concentration in tank 2 at time $=\mathrm{t}+\Delta \mathrm{t}(\underline{\mathrm{M}})$.

Equation 13 assumes a constant $V_{2}$ value during the time interval. Substituting 2 and 4 in 13 gives

$$
\mathrm{C}_{\mathrm{T} 2, \mathrm{t}}=\frac{\mathrm{V}_{2} \mathrm{C}_{\mathrm{T} 2, \mathrm{to}}+\mathrm{C}_{1}\left(\mathrm{t}-\mathrm{t}_{\mathrm{o}}\right)\left[\mathrm{q}_{\mathrm{CW}}-\mathrm{q}_{\mathrm{BW}}(1-\mathrm{Ea})\right]}{\mathrm{q}_{\mathrm{BW}} \mathrm{Ea}\left(\mathrm{t}-\mathrm{t}_{\mathrm{o}}\right)+\mathrm{V}_{2}} .
$$

It was not feasible to find an analytical solution for Equation 14 after incorporating Equations 2, 4, and 9 in it. Therefore, numerical integration was used by dividing the total test period into small intervals, calculating $C_{1}$ for each interval (using Equation 9), then calculating $\mathrm{C}_{\mathrm{T} 2}$ at the end of each interval using Equation 14. The model fitting was iterated, by varying the value for stage efficiency $\left(\mathrm{E}_{\mathrm{a}}\right)$, until values for $\mathrm{C}_{\mathrm{T} 1}$ and $\mathrm{C}_{\mathrm{T} 2}$ which matched the experimental values were yielded by the model. 


\section{RESULTS AND DISCUSSION}

\subsection{Solvent Recovery Using Diluent Contact}

Table 2 lists the observations regarding the appearance of the aqueous phase, solvent, and diluent in both diluent reservoirs during the solvent recovery test. The appearance of the aqueous phase was always very cloudy during the test while the three organic phases (solvent and two diluents) were clear, hazy, or slightly cloudy. This suggests that the contactors were operating under an aqueous-continuous mode, despite the attempt to make it organic-continuous by using an O/A ratio of 3 in the two diluent contact stages. An organic-continuous operation is desired to minimize the entrainment.

Table 2. Liquid Appearance During Solvent Recovery Test

\begin{tabular}{|c|c|c|c|c|c|}
\hline $\begin{array}{c}\text { Cumulative } \\
\text { Time (hr) }\end{array}$ & $\begin{array}{c}\text { Length of } \\
\text { Time } \\
\text { Interval (hr) }\end{array}$ & $\begin{array}{c}\text { Appearance of } \\
\text { Aqueous } \\
\text { Phase }^{(a)}\end{array}$ & $\begin{array}{c}\text { Appearance } \\
\text { of Solvent }^{(a)}\end{array}$ & $\begin{array}{c}\text { Appearance of } \\
\text { Diluent in } \\
\text { First Beaker }\end{array}$ & $\begin{array}{c}\text { Appearance of } \\
\text { Diluent in } \\
\text { Second Beaker }\end{array}$ \\
\hline 2 & 2 & V cldy & Hazy & Clr & Clr \\
\hline 4 & 2 & V cldy & Hazy & Clr & Clr \\
\hline 5.75 & 1.75 & V cldy & Sl cldy & Clr & Clr \\
\hline 8.75 & 3 & V cldy & Sl cldy & Clr & Crys clr \\
\hline 10.75 & 2 & V cldy & Hazy & Clr & Clr \\
\hline 14.75 & 4 & V cldy & Hazy & Hazy & Hazy \\
\hline 17.3 & 2.55 & V cldy & Hazy & Hazy & Hazy \\
\hline 19.8 & 2.5 & V cldy & Hazy & Hazy & Hazy \\
\hline
\end{tabular}

(a) Crys clr= crystal clear, Clr= clear, SI cldy= slightly cloudy, V cldy= very cloudy.

Table 3 shows the amounts of organic liquids in the solvent, first diluent, and second diluent reservoirs at the beginning and end of the solvent recovery test. Because entrainment exceeded the expected level of $121 \mathrm{ppm}$, diluent was added to both diluent reservoirs during the test. These are also shown in Table 3. Based on the liquid volumes shown in Table 3 , an average rate of liquid volume change (in $\mathrm{mL} / \mathrm{min}$ ) was calculated. At the end of every day of the test period, the aqueous liquid was allowed to settle overnight in a separation funnel and the organic phase was separated and disposed of. The amount of separated organic phase was not recorded, but it is estimated to be $40-80 \mathrm{ml}$ per day.

Table 3. Changes in Liquid Volume During Solvent Recovery Test

\begin{tabular}{|l|c|c|c|c|}
\hline Organic Liquid & $\begin{array}{c}\text { Liquid Volume } \\
\text { at Start }(\mathbf{m L})\end{array}$ & $\begin{array}{c}\text { Liquid Volume } \\
\text { at End }(\mathbf{m L})\end{array}$ & $\begin{array}{c}\text { Liquid Added } \\
\text { During Test } \\
(\mathbf{m L})\end{array}$ & $\begin{array}{c}\text { Rate of Volume } \\
\text { Change } \\
(\mathbf{m L} / \mathbf{m i n})^{(\mathbf{b})}\end{array}$ \\
\hline Solvent & 300 & 295 & 0 & $-4.21 \mathrm{E}-03$ \\
\hline First Diluent & 200 & 135 & 200 & $-2.23 \mathrm{E}-01$ \\
\hline Second Diluent & 200 & 245 & 150 & $-8.84 \mathrm{E}-02$ \\
\hline
\end{tabular}

(a) Liquid added $5.75 \mathrm{hr}$ after starting the test.

(b) Negative rates indicate volume loss. 
It is observed from Table 3 that significant organic loss was seen in the first and second diluent reservoirs. A small fraction of this loss is likely due to Isopar ${ }^{\circledR}$ L evaporation, but the bulk of the loss is due to entrainment occurring in the aqueous phase exiting both diluent contact stages. To replenish, 200 and $150 \mathrm{~mL}$ of fresh diluent were added to the first and second diluent reservoirs, respectively. These amounts were added 5.75 hours after starting the test. The rates of volume change in all three organic reservoirs, shown in Table 3, were used to calculate the values for $\mathrm{q}_{\mathrm{DW}}, \mathrm{q}_{\mathrm{CW}}$, and $\mathrm{q}_{\mathrm{BW}}$ of the model, as detailed in Appendix $\mathrm{B}$. These values were found to be $0.015,0.24$, and $0.33 \mathrm{~mL} / \mathrm{min}$, respectively. These values correspond to $0.015 \%, 0.24 \%$, and $0.33 \%$ organic-in-aqueous entrainment in the aqueous flow leaving the solvent, first, and second diluent stages, respectively. These values are higher than the expected entrainment level of $121 \mathrm{ppm}$ (or 0.012\%) [ARAFAT-2001] but are still well within the acceptable limit for normal-operation entrainment, which is $<1 \%$. The higher-than-expected rates of organic entrainment in the diluent stages are a concern. If they cannot be reduced, then gains achieved by recovering the solvent components in the diluent contact stages will be partially or totally offset by the high rate of diluent entrainment. If no action is taken to recover the entrained diluent (for example, by using a coalescer or centrifuge), an optimum solvent recovery limit has to be established, beyond which more BOBCalixC6 and modifier are lost in the entrained diluent than are recovered by the diluent-contact stages. In this case the use of diluent-contact for solvent recovery becomes less attractive.

BOBCalixC6 and modifier concentrations in samples taken at different time intervals of the 19.8-hour test were measured by ORNL and are given in Table 4. Also reported are average liquid volumes in the first and second diluent reservoirs, which were used in the model calculations. Concentrations of BOBCalixC6 and modifier in the solvent reservoir average 7.9E3 and $0.29 \underline{M}$ with standard deviations of 7 and 4\%, respectively. Compared with the fresh solvent concentrations, $0.01 \underline{\mathrm{M}}$ BOBCalixC6 and $0.5 \underline{\mathrm{M}}$ modifier, the measured concentrations suggest a possible 20-40\% measurement error. BOBCalixC6 and modifier loss through partitioning is very small and does not explain this difference. Moreover, this margin of error does not explain some of the unexpected trends in the data. For example, the second sample from the first diluent container has less BOBCalixC6 (by five-fold) and modifier (by two-fold) than the first sample. This concentration should increase with time during the solvent recovery test. Another important observation of the concentrations reported in Table 4 is the difference in the percentage of recovery of BOBCalixC6 and modifier in the diluent. By examining, for example, the last line in Table 4, we see that the concentrations of BOBCalixC6 and modifier in the first diluent reservoir are 7.3 and 3\% that of the fresh CSSX solvent, respectively. Based on our key assumption that most of the solvent loss occurs by entrainment, the two percentages are should be equal. Experimental error in concentration measurements seems the most likely explanation for such differences. 
Table 4. BOBCalixC6 and Modifier Concentrations During Solvent Recovery Test

\begin{tabular}{|c|c|c|c|c|c|c|c|c|}
\hline \multirow[b]{2}{*}{$\begin{array}{c}\text { Cumulative } \\
\text { Time at End } \\
\text { of Interval } \\
\text { (hr) }\end{array}$} & \multirow[b]{2}{*}{$\begin{array}{c}\text { Liquid } \\
\text { Volume in } \\
\text { First Diluent } \text { Stage }^{(\mathrm{a})}(\mathrm{L}) \\
\end{array}$} & \multirow{2}{*}{$\begin{array}{l}\text { Liquid } \\
\text { Volume in } \\
\text { Second } \\
\text { Diluent } \\
\text { Stage }^{(a)} \text { (L) }\end{array}$} & \multicolumn{2}{|c|}{ Diluent Reservoir No. 1} & \multicolumn{2}{|c|}{ Diluent Reservoir No. 2} & \multicolumn{2}{|c|}{$\begin{array}{c}\text { Solvent } \\
\text { Reservoir }^{(\mathbf{b})}\end{array}$} \\
\hline & & & $\begin{array}{c}\text { BOBCalixC6 } \\
\text { Conc. (M) }\end{array}$ & $\begin{array}{l}\text { Modifier } \\
\text { Conc. (M) }\end{array}$ & \begin{tabular}{|} 
BOBCalixC6 \\
Conc. (M)
\end{tabular} & \begin{tabular}{|c|} 
Modifier \\
Conc. (M)
\end{tabular} & $\begin{array}{l}\text { BOBCalixC6 } \\
\text { Conc. }(\mathrm{M})^{(\mathrm{C})}\end{array}$ & $\begin{array}{c}\text { Modifier } \\
\text { Conc. } \\
\text { (M) }^{(c)}\end{array}$ \\
\hline $\begin{array}{l}2 \\
4\end{array}$ & & & & & & & 8.50E-03 & 3.00E-01 \\
\hline 5.75 & 0113 & 0163 & 130 & $9.50 \mathrm{E}-03$ & & 5.60E-03 & & \\
\hline 8.75 & 0.308 & 0.295 & $1.30 \mathrm{E}-04$ & $4.10 \mathrm{E}-03$ & 8.00 & $2.20 \mathrm{E}-03$ & $8.30 \mathrm{E}-03$ & 2.90E-01 \\
\hline 10.75 & 0.233 & 0.295 & $1.70 \mathrm{E}-04$ & 7.50E-03 & 1.10E-04 & $5.50 \mathrm{E}-03$ & & \\
\hline 14.75 & 0.200 & & $2.90 \mathrm{E}-04$ & 9.70E-03 & 1.40 & 4.60E-03 & 7.30E-03 & 2.90E-01 \\
\hline 17 & & & & 1.60E-02 & 2.5 & $1.20 \mathrm{E}-02$ & & \\
\hline 19.8 & 0.153 & 0.248 & 7.30E-04 & 1.50E-02 & $2.90 \mathrm{E}-04$ & $8.20 \mathrm{E}-03$ & $7.60 \mathrm{E}-03$ & $2.70 \mathrm{E}-01$ \\
\hline
\end{tabular}

(a) Liquid volume includes the amounts in the reservoir, connection tubes, and contactor stage.

(b) Liquid volume in the solvent reservoir barely changed, as reflected by Table 3.

(c) Initial concentrations were made up to be 0.01 and $0.5 \mathrm{M}$ for the extractant and modifier. The analytical results appear to show a bias that cannot be explained.

In order to obtain the stage efficiency for the diluent contact stages, we performed iterative model calculations. The total test period (1,188 minutes) was divided into 51 time intervals. A value was assumed for the stage efficiency $\left(\mathrm{E}_{\mathrm{a}}\right)$, then for each time interval, the BOBCalixC6 concentration in the first diluent beaker was calculated using Equations 7-9 and the calculated values for $\mathrm{q}_{\mathrm{CW}}$ and $\mathrm{q}_{\mathrm{DW}}$. $\mathrm{C}_{1}$ was then calculated using Equation 2. The three values, $\mathrm{C}_{1}, \mathrm{q}_{\mathrm{CW}}$, and $\mathrm{q}_{\mathrm{BW}}$ were then used to calculate the BOBCalixC6 concentration in the second diluent tank $\left(\mathrm{C}_{\mathrm{T} 2}\right)$ using Equation 14. In calculating $\mathrm{C}_{\mathrm{T} 2}$, the calculated concentration for the previous interval was used as $\mathrm{C}_{\mathrm{T} 2 \text {,to }}$. A sample calculation for the model is shown in Table 5. The model-calculated concentrations were then compared with the actual concentrations obtained experimentally, listed in Table 4. To compare the actual and model concentrations quantitatively, the model-predicted concentration was divided by the measured concentration, as shown in Table 5. This ratio was called "model prediction accuracy". A ratio that is closer to 1.0 indicates a better model prediction. Average and standard deviation values for the model prediction accuracy were then calculated for all measured concentrations in both diluent reservoirs. 
Table 5. Model Sample Calculation ${ }^{(a)}$ Using $E_{a}=0.97, C o=0.01 \underline{M}$, and $C_{T 1,0}=0$

\begin{tabular}{|c|c|c|c|c|c|c|c|c|c|c|c|}
\hline $\begin{array}{l}\text { Time } \\
(\mathbf{m i n})\end{array}$ & $\begin{array}{c}\text { Average } \\
\mathrm{V}_{1}(\mathrm{~L})\end{array}$ & $\begin{array}{c}\text { Average } \\
\mathrm{V}_{2}(\mathrm{~L})\end{array}$ & A & B & $\begin{array}{c}\text { Model- } \\
\text { Predicted } \\
\mathrm{C}_{1}(\underline{\mathrm{M}}) \\
\end{array}$ & $\begin{array}{c}\text { Model- } \\
\text { Predicted } \\
\mathrm{C}_{\mathrm{T} 1}(\underline{\mathrm{M}}) \\
\end{array}$ & $\begin{array}{c}\text { Model- } \\
\text { Predicted } \\
\mathrm{C}_{\mathrm{T} 2} \text { (佥) }\end{array}$ & $\begin{array}{c}\text { Measured } \\
\mathrm{C}_{\mathrm{T} 1}(\mathrm{M})\end{array}$ & $\begin{array}{c}\text { Measured } \\
\mathrm{C}_{\mathrm{T} 2}(\mathrm{M}) \\
\end{array}$ & $\begin{array}{c}\text { Model- } \\
\text { Predicted } \\
\mathrm{C}_{\mathrm{T} 1} / \\
\text { Measured }^{\left({ }^{2}\right)} \\
\mathrm{C}_{\mathrm{T} 1} \\
\end{array}$ & \begin{tabular}{|c|} 
Model- \\
Predicted \\
$\mathbf{C}_{\mathrm{T} 2} /$ \\
Measured \\
$\mathrm{C}_{\mathrm{T} 2}$ (b) \\
\end{tabular} \\
\hline 0 & 0.2 & 0.2 & $.76 \mathrm{E}-07$ & $15 \mathrm{E}-03$ & $3.00 \mathrm{E}-04$ & $0 \mathrm{E}+00$ & 0 & & & & \\
\hline 119 & 0.195 & 0.198 & 3.85E-07 & $1.18 \mathrm{E}-03$ & $3.41 \mathrm{E}-04$ & 4.27E-05 & 3.99E-05 & 8.70E-05 & & 0.49 & 1.08 \\
\hline 238 & 0.17 & 0.185 & 4.42E-07 & $1.36 \mathrm{E}-03$ & 3.87E-04 & 8.98E-05 & $8.11 \mathrm{E}-05$ & 1.55E-05 & -04 & 5.79 & 0.81 \\
\hline 356 & & & $5.25 \mathrm{E}-07$ & $1.61 \mathrm{E}-03$ & & $1.42 \mathrm{E}-04$ & $1.26 \mathrm{E}-04$ & 04 & & 1.10 & 1.05 \\
\hline 523 & 308 & 295 & $2.44 \mathrm{E}-07$ & 7.49E-04 & $4.02 \mathrm{E}-04$ & 1.06E-04 & $1.52 \mathrm{E}-04$ & 1.30E-04 & & 0.81 & 1.89 \\
\hline 642 & 0.233 & 95 & $3.22 \mathrm{E}-07$ & $9.90 \mathrm{E}$ & 4.49 & $1.53 \mathrm{E}$ & 1.71 & -04 & 4 & 0.90 & 1.56 \\
\hline 879 & & 288 & 3.76E-07 & 1.15E-03 & 5.01E-04 & 2.08E-04 & 2.12E-04 & \begin{tabular}{|l|}
$2.90 \mathrm{E}-04$ \\
\end{tabular} & $1.40 \mathrm{E}-04$ & 0.72 & 1.51 \\
\hline 1045 & 0.185 & & $4.06 \mathrm{E}-07$ & $1.25 \mathrm{E}-03$ & 5.30E-04 & 2.37E-04 & $2.42 \mathrm{E}-04$ & 4.00E-04 & & 0.59 & 0.97 \\
\hline 1188 & 0.153 & 0.248 & 4.91E-07 & $1.51 \mathrm{E}-03$ & 5.63E-04 & 2.71E-04 & $2.68 \mathrm{E}-04$ & 7.30E-04 & $2.90 \mathrm{E}-04$ & 0.37 & 0.93 \\
\hline
\end{tabular}

(a) See Section 3 for definitions of terms.

(b) This ratio is defined as "model prediction accuracy".

Figure 5 shows the average and standard deviation values for the model prediction accuracy as a function of stage efficiency. Stage efficiency for the diluent-contact stages is identified by an average model prediction accuracy value equal or close to 1.0, and a minimum standard deviation. By examining Figure 5, the stage efficiency is found to be between 0.94 and 0.95 .

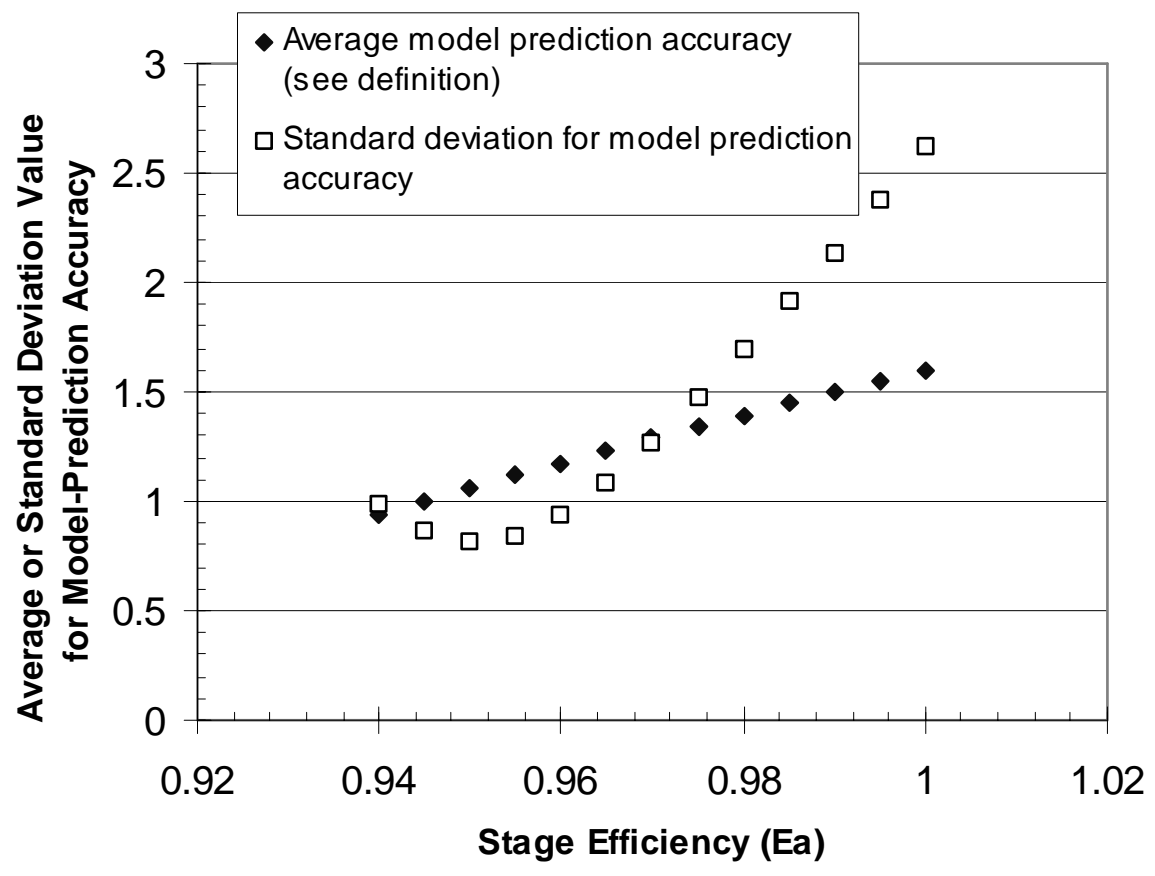

Figure 5. Average and Standard Deviation for Model Prediction Accuracy 
In order to get a feeling for the relative effects of changes in organic entrainment and stage efficiency on the performance of the solvent recovery system, we performed several model calculations. Figure 6 shows the effects of organic entrainment and stage efficiency $\left(\mathrm{E}_{\mathrm{a}}\right)$ on model-predicted values for BOBCalixC6 concentration after 20 hours in the first and second diluent reservoirs. The model predictions were obtained, for comparison purposes, using a solvent recovery system similar to that described in Figure 2, except that the organic entrainment was assumed to be equal for all three stages. Figure 6 indicates that organic entrainment has a more significant effect on the BOBCalixC6 concentration than stage efficiency. For example, an increase in organic entrainment from 0.012 to $0.2 \%$ (both of which are well within the $1 \%$ limit for normal operation) at $\mathrm{E}_{\mathrm{a}}=0.95$ increases the BOBCalixC6 concentration in the first diluent reservoir by $800 \%$. On the other hand, at $0.012 \%$ entrainment, increasing the stage efficiency from 0.8 to 1.0 increases the BOBCalixC6 concentration in the first reservoir only by $24 \%$. These trends indicate that the solvent recovery by diluent contact process is far more sensitive to entrainment levels than to stage efficiency.
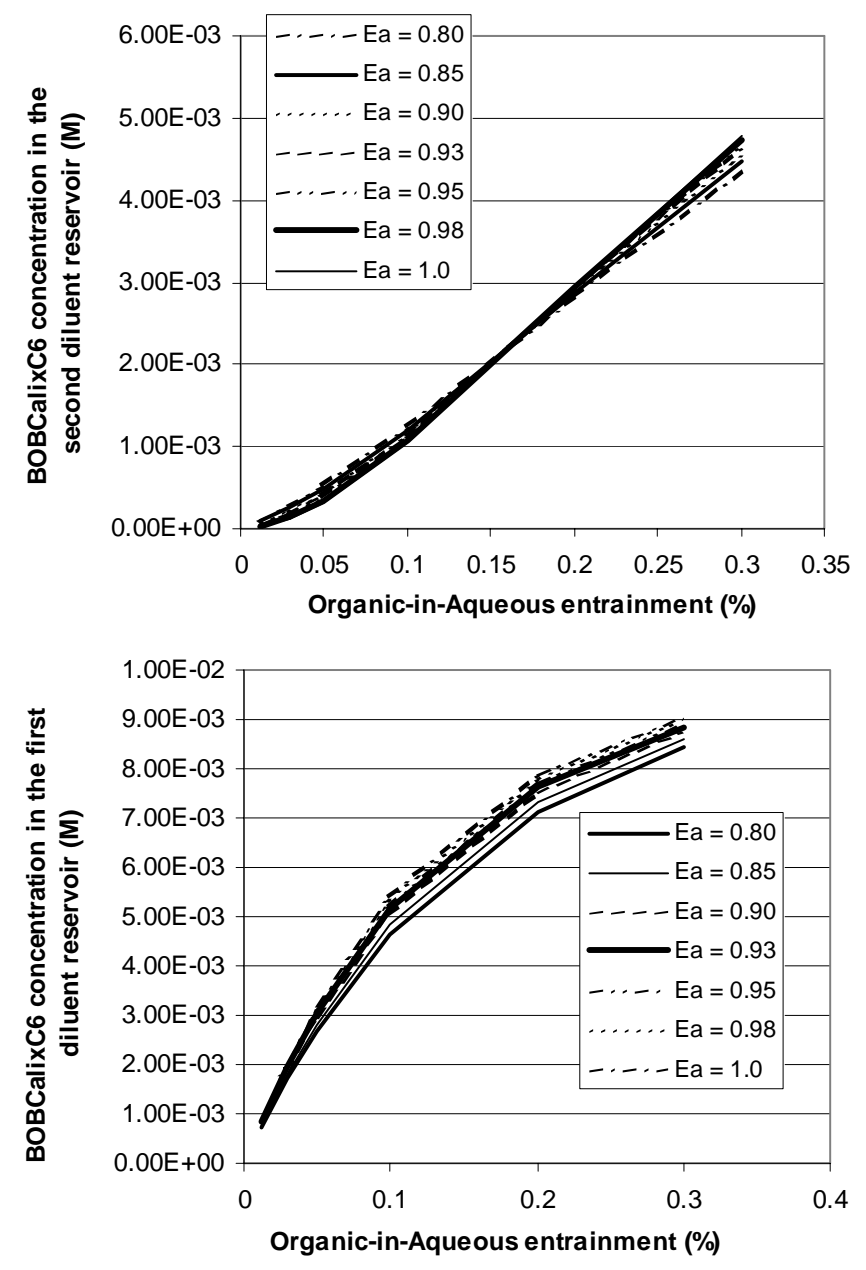

Figure 6. Effects of Organic Entrainment and Stage Efficiency on BOBCalixC6 in First and Second Diluent Reservoirs 


\subsection{Vacuum Distillation}

In the actual CSSX plant, after the diluent for BOBCalixC6 and modifier recovery is used in the diluent-contact stages, the diluent can be processed by one of two methods: (1) direct use after concentration adjustment, or (2) concentration by vacuum distillation. In the first method, amounts of the three solvent components-BOBCalixC6, modifier, and TOA-are added to the diluent used in solvent recovery to reach the concentrations of the fresh CSSX solvent. This requires knowledge of the concentration of these compounds in the diluent after its use in solvent recovery, which can be obtained by analyzing a sample of the diluent. After reaching the CSSX solvent concentrations, the diluent (now a full CSSX solvent) can be used in the plant as a CSSX solvent.

In the second method, concentration by vacuum distillation, pre-determined amounts of diluent are removed by vacuum distillation from the spent diluent used in the solvent recovery system. As the diluent is evaporated, the concentrations of BOBCalixC6 and modifier, which are much less volatile than the Isopar ${ }^{\circledR} \mathrm{L}$, increase in the un-evaporated diluent until it reaches the concentration of CSSX solvent. As with the first method, this process requires an accurate knowledge of BOBCalixC6 and modifier concentrations in the spent diluent. It also requires post-concentration analysis to verify the final concentrations.

In order to evaluate vacuum distillation for concentrating BOBCalixC6 and the modifier in the spent diluent, we performed a test using the spent diluent from the 20-hr solvent recovery test. The starting concentrations of BOBCalixC6 and modifier in the two diluent solutions are the concentrations at the end of the 20-hr solvent recovery test: $7.3 \mathrm{E}-4 \underline{\mathrm{M}}$ BOBCalixC6 and $1.5 \mathrm{E}-2 \underline{\mathrm{M}}$ modifier in the first diluent reservoir, and $2.9 \mathrm{E}-4 \underline{\mathrm{M}}$ BOBCalixC6 and 8.2E-3 $\underline{\mathrm{M}}$ modifier in the second diluent reservoir. The concentrations of BOBCalixC6 were $7.3 \%$ and $2.9 \%$ of the CSSX solvent concentration $(0.01 \underline{\mathrm{M}})$ in the first and second diluent containers, respectively. Concentrations of modifier were $3 \%$ and $1.6 \%$ of solvent concentration $(0.5 \underline{\mathrm{M}})$ in the first and second containers, respectively. Fifty milliliters of spent diluent were used in the test. Evaporation did not start until the oil bath temperature reached $132{ }^{\circ} \mathrm{C}$. Evaporation continued for about 10 minutes, during which more than $95 \%$ of the diluent evaporated. Table 6 shows the concentration of BOBCalixC6 and modifier in the concentrated diluent sample. 
Table 6. Concentration of BOBCalixC6 and Modifier in Concentrated and Condensed Diluent

\begin{tabular}{|l|c|c|c|c|}
\hline \multicolumn{1}{|c|}{ Sample } & $\begin{array}{c}\text { BOBCalixC6 } \\
\text { Concentration in } \\
\text { Diluent After } \\
\text { Evaporation (M) }\end{array}$ & $\begin{array}{c}\text { Modifier } \\
\text { Concentration in } \\
\text { Diluent After } \\
\text { Evaporation (M) }\end{array}$ & $\begin{array}{c}\text { BOBCalixC6 } \\
\text { Concentration in } \\
\text { Diluent After } \\
\text { Evaporation (as \% of of } \\
\text { CSSX Solvent) }\end{array}$ & $\begin{array}{c}\text { Modifier } \\
\text { Concentration in } \\
\text { Diluent After } \\
\text { Evaporation (as \% } \\
\text { of CSSX Solvent) }\end{array}$ \\
\hline $\begin{array}{l}\text { Concentrated Diluent-1st } \\
\text { Diluent Container }\end{array}$ & $1.20 \mathrm{E}-02$ & 0.42 & $120 \%$ & $84 \%$ \\
\hline $\begin{array}{l}\text { Concentrated Diluent-2nd } \\
\text { Diluent Container }\end{array}$ & $9.20 \mathrm{E}-03$ & 0.32 & $92 \%$ & $64 \%$ \\
\hline $\begin{array}{l}\text { Condensed Diluent-1st Diluent } \\
\text { Container }\end{array}$ & $\mathrm{ND}^{(\mathrm{a})}$ & $\mathrm{ND}$ & 0 & 0 \\
\hline $\begin{array}{l}\text { Condensed Diluent-2nd Diluent } \\
\text { Container }\end{array}$ & $\mathrm{ND}$ & $\mathrm{ND}$ & 0 & 0 \\
\hline
\end{tabular}

(a) Not detectable.

The BOBCalixC6 and modifier concentrations in the concentrated diluent, shown in Table 6, demonstrate the ability to increase the concentrations of both compounds in the diluent. As a percentage of CSSX solvent, BOBCalixC6 concentration went up from $7.3 \%$ to $120 \%$ (a 16-fold concentration ratio) for the first contact stage diluent, exceeding the fresh CSSX solvent concentration. For the second contact stage, the percentage went up from $2.9 \%$ to $92 \%$, a 32 fold concentration ratio. For the modifier, the percentages went up from $3 \%$ to $84 \%$ (a 28 -fold concentration ratio) and from $1.6 \%$ to $64 \%$ (a 40-fold concentration ratio) in the first and second contact stage diluent, respectively. Based on these results, vacuum distillation was judged a feasible technique for concentrating the solvent components in the diluent. However, a significant difference is observed in the concentration ratio for BOBCalixC6 and modifier in the same diluent sample, with the modifier being more concentrated. One suggested explanation was that some amount of BOBCalixC6 might have evaporated. However, no detectable amounts of BOBCalixC6 or modifier were found in the condensed diluent. Other possible explanations are the thermal degradation of BOBCalixC6 at $135{ }^{\circ} \mathrm{C}$. Previous correspondence with ORNL indicates that no significant degradation of either compound is expected up to about $140{ }^{\circ} \mathrm{C}$ [BONNESEN-2001]. Moreover, ORNL was not able to detect any thermal degradation byproducts in the diluent samples. Potential error in the analytical results remains the most likely possibility.

Analytical uncertainties limit the conclusions that can be drawn from these results. However, general trends can be established. It is recommended, therefore, to use the conclusions of this work in a qualitative, rather than quantitative, fashion. Based on test results, vacuum distillation can be used in concentrating BOBCalixC6 and modifier in the diluent used in solvent recovery. However, there are two concerns regarding its use: (1) diluent fractionation and (2) thermal degradation. Since the diluent is a mixture of different hydrocarbons with different boiling points, the lighter hydrocarbons will evaporate first during the vacuum distillation process, leaving behind the heavier, less volatile components and causing diluent fractionation. This causes the chemical composition of diluent in the concentrated samples to be different from that of fresh CSSX solvent. The second concern is associated with the possibility of thermal degradation of BOBCalixC6 and the modifier at high evaporation temperatures (up to $135{ }^{\circ} \mathrm{C}$, as found in the vacuum distillation test), although no evidence for such degradation was found during this test. 


\subsection{Economic Feasibility}

In this section, an economic comparison is established among four alternatives for solvent recovery. These are: (1) decanter tank, (2) centrifuge, (3) diluent contact in a 2-stage centrifugal contactor, and (4) no solvent recovery action. The comparison is based solely on the annual cost of solvent loss and does not include equipment or operating costs. The later costs might be significant, especially for remote operation in a hot-cell facility. Hence, the final decision regarding the most feasible technology must take these factors into consideration. The calculations presented here assume 24-hr operation for 240 days per year. It is important to keep in mind that the cost values reported here are based on certain assumptions in calculating the amounts of solvent lost when a particular method is used. When these assumptions are changed, the cost will change. Therefore, the values reported should not be used as an absolute comparison in making a selection among the processes, but rather as a sample calculation and an order-of-magnitude indicator of the differences in cost. It is also worth mentioning that other solvent recovery options could be very feasible, such as coalescers [ARAFAT-2001]. Since no experimental work was done to support the performance of these techniques, they are not included in the economic feasibility comparison. Following is a discussion of the four recovery options.

\section{Decanter Tank}

Based on droplet size distribution of entrained solvent in the aqueous phase [ARAFAT2001], a 3,500-gallon $\left(13.25 \mathrm{~m}^{3}\right)$ cylindrical decanter tank, with diameter $=2.4 \mathrm{~m}$ and height $=$ $3.0 \mathrm{~m}$, can achieve $27.5 \%$ recovery of entrained solvent in the raffinate solution and $100 \%$ recovery in the strip solution, as calculated in Appendix C. By using a decanter tank, entrained, but not dissolved (i.e., partitioned), solvent can be recovered. Based on an average $121 \mathrm{ppm}$ solvent entrainment in the aqueous phase [ARAFAT-2001], the total annual cost of lost solvent using a decanter tank is

Total annual cost $=$ cost of unrecovered entrained solvent + cost of dissolved solvent.

The cost of dissolved solvent was estimated in ARAFAT-2001 at $\$ 0.6 \mathrm{M} / \mathrm{yr}$ for $24-\mathrm{hr}$ operation 240 days per year. Also, since the calculated recovery from the strip solution is $100 \%$, the cost of unrecovered entrained solvent will be only the cost of the unrecovered amount in the raffinate solution. Hence,

Total annual cost $=0.725 \times 121 \mathrm{E}-6(\mathrm{~L}$ solvent $/ \mathrm{L}$ aqueous $) \times 81.1(\mathrm{~L}$ aqueous $/ \mathrm{min}) \times$ $900(\$ / \mathrm{L}$ solvent) x $1440(\mathrm{~min} /$ day $)$ x $240($ day $/ \mathrm{yr})+\$ 0.6 \mathrm{M}=\$ 5.3 \mathrm{M} / \mathrm{yr}$.

\section{Centrifuge}

The performance of a centrifuge in solvent recovery has not been experimentally tested. Therefore, cost estimates were based on performance estimates for a commercial centrifuge manufactured by Westfalia Inc. (Oelde, Germany), using the size distribution of entrained solvent reported in ARAFAT-2001. Using a Westfalia Disc bowl centrifuge (model TA 50) with $6,000 \mathrm{rpm}$ speed, $60-\mathrm{cm}$ bowl diameter, $250 \mathrm{~L} / \mathrm{min}$ rated capacity, and $8,000 \mathrm{~m} / \mathrm{s}^{2} \mathrm{~g}$-force, the calculated recovery is $90 \%$ and $100 \%$ of the entrained solvent in the raffinate and strip solutions, 
respectively, as shown in Appendix D. Similar to a decanter tank, a centrifuge will not recover any dissolved solvent. Based on an average 121-ppm solvent entrainment and $\$ 0.6 \mathrm{M} / \mathrm{yr}$ cost for dissolved solvent, Equation 15 gives

Total annual cost $=0.1 \times 121 \mathrm{E}-6(\mathrm{~L}$ solvent $/ \mathrm{L}$ aqueous $) \times 81.1(\mathrm{~L}$ aqueous $/ \mathrm{min}) \times 1900$ (\$/L solvent) x $1440(\mathrm{~min} /$ day) x $240($ day/yr $)+\$ 0.6 \mathrm{M}=\$ 1.24 \mathrm{M} / \mathrm{yr}$.

\section{Diluent Contact in 2-Stage Centrifugal Contactor}

Using the model developed for solvent recovery (Section 3), the amounts of BOBCalixC6 and modifier ultimately lost in the aqueous raffinate, following its diluent contact were calculated to be 5.24E-3 and $0.26 \mathrm{~mol} /$ day, respectively, as shown in Appendix E. These calculations are based on $94.5 \%$ stage efficiency, $30 \mathrm{~L}$ of diluent used in each recovery stage, and the all-at-once replacement of used diluent with fresh amounts every 24 hours. The calculation also assumes an average organic concentration of $121 \mathrm{ppm}$ in all stages. Also, diluent contact recovers both dissolved and entrained solvent components. Hence, the annual cost for lost solvent in the aqueous raffinate when diluent contact is used is calculated as

Total annual cost $=5.24 \mathrm{E}-3($ mol BOBCalixC6/day $) \times 240($ day/yr $) \times$

1150 (g BOBCalixC6/mol BOBCalixC6) x 150 (\$/g BOBCalixC6) +

0.26 mol modifier/day) x 240 (day/yr) x 338 (g modifier/mol modifier) x

$1.5(\$ / \mathrm{g}$ modifier $)=\$ 0.25 \mathrm{M} / \mathrm{yr}$.

Since no experimental work was done to evaluate the performance of the solvent recovery using diluent contact for the strip solution (i.e., no stage efficiency data are available), it was assumed the total loss in the strip solution will be proportional to its flow rate, which is $1 / 15$ that of the aqueous raffinate. Hence, the total annual cost of lost solvent when the diluent contact process is used is

Total annual cost $=(1+1 / 15) \times \$ 0.25 \mathrm{M}=\$ 0.27 \mathrm{M} / \mathrm{yr}$.

A number of factors influence the annual cost of unrecovered solvent in the process using diluent contact. These are stage efficiency, organic-in-aqueous entrainment, and the diluent volume used in the diluent contact stage. In calculating the amount of solvent lost when diluentcontact is used (Appendix E), $121 \mathrm{ppm}$ was used as an average value for organic-in-aqueous entrainment, which was obtained experimentally [ARAFAT-2001]. The stage efficiency value, $\mathrm{Ea}=0.945$, is based on the experimental findings in Section 4.1. It is likely for the entrainment level to be different than $121 \mathrm{ppm}$ in plant operation. It is also possible for stage efficiency to be different than 0.945. To assess the effects of changes in stage efficiency and organic entrainment on the cost of unrecovered solvent, the calculations in Appendix E were repeated using a range of organic entrainment and stage efficiency values and assuming $30 \mathrm{~L}$ of diluent in each diluentcontact stage. Results of these calculations, shown in Figure 7, indicate that the annual cost of unrecovered solvent is more sensitive to organic entrainment than to stage efficiency, except at low entrainment $(0.012 \%$ [120 ppm]). At organic entrainment levels of $0.03 \%$ (300 ppm) or higher, the annual cost of unrecovered solvent was affected primarily by organic entrainment. 


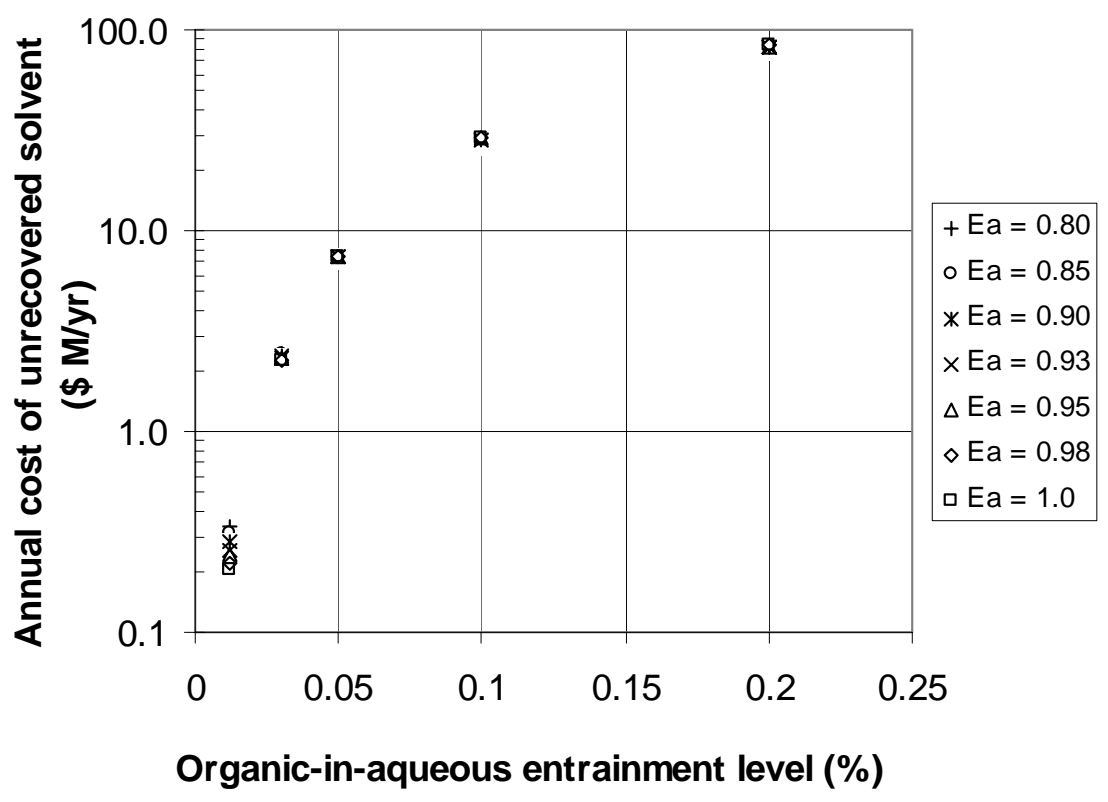

Figure 7. Effects of Organic Entrainment and Stage Efficiency on Annual Cost of Unrecovered Solvent in 2-Stage Diluent-Contact Unit for Solvent Recovery

Cost calculations of unrecovered solvent were also performed using a range of diluent volumes in the contact stages, at organic entrainment of $121 \mathrm{ppm}$ and $\mathrm{Ea}=0.945$, as shown in Figure 8. Figure 78 reveals that the unrecovered solvent cost is more sensitive to diluent volumes in the diluent-contact stages at the lower diluent volumes.

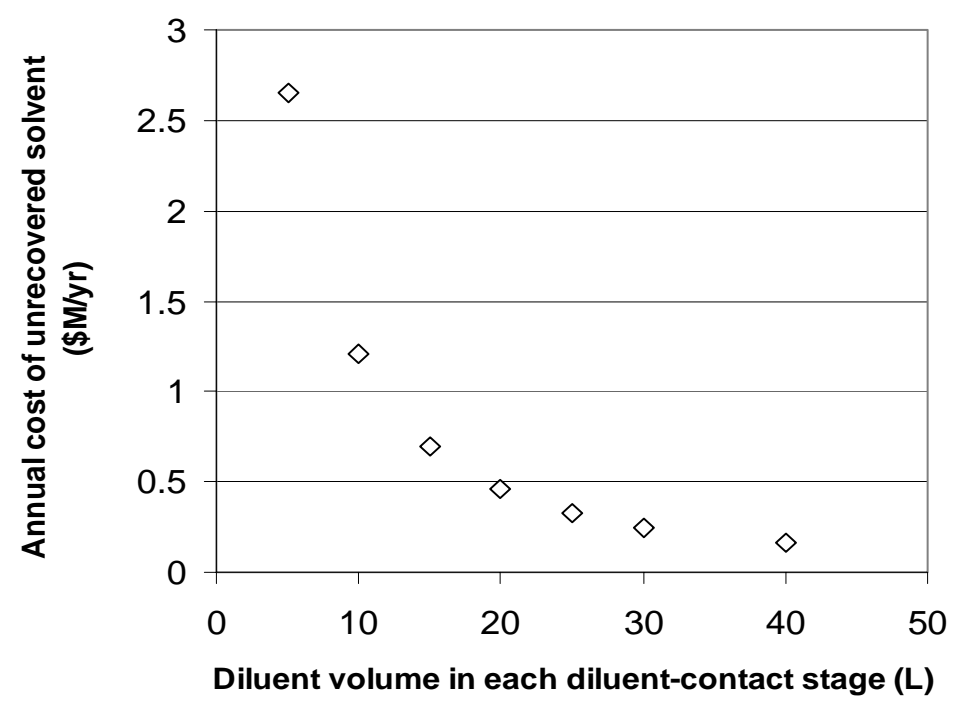

Figure 8. Effect of Diluent Volume in Diluent-Contact Stages on Annual Cost of Unrecovered Solvent in 2-Stage Diluent-Contact Unit for Solvent Recovery at Entrainment $=121 \mathrm{ppm}$ and $\mathrm{E}_{\mathrm{a}}=\mathbf{0 . 9 4 5}$ 


\section{No Solvent Recovery Action}

At an average $121 \mathrm{ppm}$ solvent entrainment in the aqueous phase, the annual cost for entrained solvent, both in raffinate and strip solutions, was calculated in ARAFAT-2001 and found to be about $\$ 7 \mathrm{M} / \mathrm{yr}$. Using Equation 15, the total annual cost for solvent loss will be

Total annual cost $=\$ 7 \mathrm{M}+\$ 0.6 \mathrm{M}=\$ 7.6 \mathrm{M} / \mathrm{yr}$.

Table 7 shows a comparison of the cost of lost solvent for each of the four solvent recovery options and some of the technical and operating cost issues related to each option. From a cost standpoint, the two-stage diluent contact would be the most attractive choice. However, other factors, including the issues discussed in Table 7, must be considered in the choice of solvent recovery technique.

Table 7. Comparison of Solvent Recovery Options

\begin{tabular}{|c|c|c|c|}
\hline $\begin{array}{l}\text { Solvent Recovery } \\
\text { Technique }\end{array}$ & $\begin{array}{l}\text { Annual Cost of } \\
\text { Solvent Loss } \\
\text { (million \$/yr) }\end{array}$ & Other Cost Issues $^{(\mathbf{b})}$ & Technical Issues \\
\hline Decanter tank & 5.3 & $\begin{array}{l}\text { - Not best suited for expected } \\
\text { levels of entrainment. Will } \\
\text { require elaborate control } \\
\text { system. }\end{array}$ & $\begin{array}{l}\text { - Large tank volume } \\
\text { - Low organic volume } \\
\text { makes organic removal } \\
\text { and feeding to tank } \\
\text { difficult, see [ARAFAT- } \\
\text { 2001] }\end{array}$ \\
\hline Centrifuge & 1.2 & None & Not tested experimentally \\
\hline $\begin{array}{l}\text { 2-stage diluent } \\
\text { contact }\end{array}$ & 0.27 & $\begin{array}{l}\text { - Possible cost of post- } \\
\text { contactor coalescer or } \\
\text { centrifuge } \\
\text { - Capital and operating cost of } \\
\text { vacuum distillation } \\
\text { - Cost of chemical analysis for } \\
\text { concentration monitoring } \\
\text { - Cost sensitivity to } \\
\text { entrainment and volume of } \\
\text { diluent used }\end{array}$ & $\begin{array}{l}\text { - Need for process testing } \\
\text { in strip section } \\
\text { - Potential high } \\
\text { entrainment in diluent- } \\
\text { contact stages and need } \\
\text { for post-recovery } \\
\text { separation } \\
\text { - Need for post-recovery } \\
\text { treatment (vacuum } \\
\text { distillation or concentration } \\
\text { make-up) }\end{array}$ \\
\hline No recovery action & 7.6 & None & $\begin{array}{l}\text { Defense Waste } \\
\text { Processing Facility } \\
\text { (DWPF) and saltstone } \\
\text { limitations on organic } \\
\text { contents }\end{array}$ \\
\hline
\end{tabular}

(a) See text for design specifications.

(b) Does not include cost of purchasing, installing, or operating solvent recovery equipment. 


\section{ACKNOWLEDGMENTS}

This work was supported by the U.S. Department of Energy, Office of Environmental Management, through (1) the Office of Project Completion and (2) the Tank Focus Area of the Office of Science and Technology under Contract W-31-109-Eng-38 with Argonne National Laboratory, managed by the University of Chicago.

\section{REFERENCES}

ARAFAT-2001

H. A. Arafat, M. C. Hash, A. S. Hebden, and R. A. Leonard, Characterization and Recovery of Solvent Entrained During the Use of Centrifugal Contactors, ANL Letter Report ANL/CMT/CSSX-2001/05 (2001).

BONNESEN-2001

P. V. Bonnesen, private communication (2001).

EXXON-2000

ExxonMobil Lubricants \& Petroleum Specialties, Material Safety Data Sheet (MSDS) for Isopar $^{\circledR}$ L, http://www2.exxonmobil.com (2000).

HODGES-2000

M.E. Hodges, Design Input-Caustic Side Solvent Extraction Flowsheet-Proof of Concept Testing, Westinghouse Savannah River Company Report HLW-SDT-2000-000356 (2000).

LEONARD-2000

R. A. Leonard, S. B. Aase, H. A. Arafat, C. Conner, J. R. Falkenberg, and G. F. Vandegrift, Proof-of-Concept Flowsheet Tests for Caustic-Side Solvent Extraction of Cesium from Tank Waste, Argonne National Laboratory Report ANL-00/30 (2000).

LEONARD-2001

R. A. Leonard, S. B. Aase, H. A. Arafat, D. B. Chamberlain, C. Conner, J. R. Falkenberg, M. C. Regalbuto, and G. F. Vandegrift, Multi-Day Test of the Caustic-Side Solvent Extraction Flowsheet for Cesium Removal from a Simulated SRS Tank Waste, Argonne National Laboratory Report ANL-02/11 (2001).

\section{LEVENSON-2000}

M. Levenson et al., Alternatives for High-Level Waste Salt Processing at the Savannah River Site, National Research Council, National Academy Press, Washington, DC (2000). 
MASKARINEC-2001

M. P. Maskarinec, J. E. Caton, and T. L. White, Analytical Methods Development in Support of the Caustic Side Solvent Extraction System, Oak Ridge National Laboratory Report ORNL/TM-2001/130 (2001).

MOYER-2001

B. A. Moyer, P. V. Bonnesen, J. E. Caton, C. R. Duchemin, T. G. Levitskaia, F. V. Sloop, S. D. Alexandratos, G. M. Brown, L. H. Delmau, T. J. Haverlock, M. P. Maskarinec, and C. L. Stine, Caustic-Side Solvent Extraction Chemical and Physical Properties: Progress in FY2000 and FY2001, Oak Ridge National Laboratory Report CERS/SR/SX/019, Rev. 0 (2001). 


\section{APPENDIX A. HYDRAULIC TESTS PERFORMED TO CHECK 4-CM CONTACTORS USED DURING SOLVENT RECOVERY TEST}

Table A-1. Zero-Point Test Results for 4-cm Contactors Used in Solvent Recovery Tests

\begin{tabular}{|c|l|c|c|c|c|c|}
\hline & & \multicolumn{3}{|c|}{ No-Flow Volumes } & Apparent \\
\cline { 3 - 6 } Rotor No. & $\begin{array}{c}\text { Volume } \\
\text { Outside Rotor } \\
(\mathbf{m L})\end{array}$ & $\begin{array}{c}\text { Volume } \\
\text { Inside Rotor } \\
(\mathbf{m L})\end{array}$ & $\begin{array}{c}\text { Total } \\
\text { Volume } \\
(\mathbf{m L})\end{array}$ & $\begin{array}{c}\text { Zero-Point } \\
\text { Flow Rate } \\
(\mathbf{m L} / \mathbf{m i n})\end{array}$ & $\begin{array}{c}\text { More-Dense- } \\
\text { Phase Weir } \\
\text { Radius (mm) }\end{array}$ \\
\hline 1 & Extraction & 8.0 & 70.0 & 78.0 & 337 & 8.50 \\
\hline 2 & Diluent contact 1 & 2.0 & 70.0 & 72.0 & 255 & 8.41 \\
\hline 3 & Diluent contact 2 & 7.8 & 70 & 77.8 & 302 & 8.46 \\
\hline
\end{tabular}

Table A-2. Single-Stage, Two-Phase Test Results for 4-cm Contactors Used in Solvent Recovery Tests

\begin{tabular}{|c|c|c|c|c|c|c|c|}
\hline $\begin{array}{l}\text { Aqueous } \\
\text { Phase }\end{array}$ & $\begin{array}{l}\text { O/A Flow } \\
\text { Ratio }\end{array}$ & $\begin{array}{c}\text { Total Flow Rate, } \\
\mathrm{mL} / \mathrm{min}\end{array}$ & $\begin{array}{c}\text { Initial Continuous } \\
\text { Phase }^{(a)}\end{array}$ & $\begin{array}{c}0 \text { in } A, \\
\%\end{array}$ & $\begin{array}{c}\text { Appearance } \\
\text { of } \mathbf{A} \\
\text { Phase }^{(b)}\end{array}$ & $A$ in $0, \%$ & $\begin{array}{l}\text { Appearance } \\
\text { of O Phase }\end{array}$ \\
\hline $\begin{array}{c}\text { Simple SRS } \\
\text { simulant }\end{array}$ & 0.33 & 130 & A & 0 & Cldy & 0 & V cldy \\
\hline " & 0.33 & 130 & 0 & 0 & Cldy & 0 & V cldy \\
\hline$"$ & 1 & 130 & A & 0 & V cldy & 0 & Hazy \\
\hline$"$ & 1 & 130 & 0 & 0 & Cldy & 0 & Hazy \\
\hline$"$ & 0.33 & 170 & $A$ & 0 & V cldy & 0.6 & Cldy \\
\hline$"$ & 0.33 & 170 & 0 & 0 & Cldy & 0 & Hazy \\
\hline$"$ & 0.33 & 200 & $A$ & \begin{tabular}{|l|} 
Trace \\
\end{tabular} & V cldy & 1.4 & Cldy \\
\hline$"$ & 0.33 & 200 & 0 & 0 & V cldy & 5.9 & V cldy \\
\hline " & 1 & 200 & A & 0 & V cldy & 0 & Cldy \\
\hline " & 1 & 200 & 0 & 0 & V cldy & 0 & Cldy \\
\hline$"$ & 3 & 200 & A & 0 & $\checkmark$ cldy & 0 & V cldy \\
\hline " & 3 & 200 & 0 & 0 & V cldy & 0 & V cldy \\
\hline " & 0.33 & 250 & $A$ & 0 & V cldy & 7.6 & V cldy \\
\hline$"$ & 0.33 & 250 & O & 0 & V cldy & 8.2 & V cldy \\
\hline " & 1 & 250 & A & 0 & V cldy & 0 & V cldy \\
\hline$"$ & 1 & 250 & O & 0 & V cldy & 0 & V cldy \\
\hline$"$ & 3 & 250 & $A$ & 0 & V cldy & Trace & V cldy \\
\hline " & 3 & 250 & O & 0 & V cldy & 0 & V cldy \\
\hline$"$ & 0.33 & 300 & A & 0 & V cldy & 8.2 & V cldy \\
\hline$"$ & 0.33 & 300 & o & 0 & V cldy & 10.7 & V cldy \\
\hline$"$ & 1 & 300 & $A$ & 0 & V cldy & 8.1 & V cldy \\
\hline " & 1 & 300 & 0 & 0 & V cldy & 0.6 & V cldy \\
\hline " & 3 & 300 & A & 0 & V cldy & 0 & V cldy \\
\hline " & 3 & 300 & 0 & 0 & V cldy & 0 & V cldy \\
\hline$"$ & 3 & 360 & $A$ & Trace & V cldy & 0 & V cldy \\
\hline " & 3 & 360 & 0 & 0 & Cldy & 0 & V cldy \\
\hline$"$ & 3 & 420 & A & 0 & V cldy & trace & V cldy \\
\hline " & 3 & 420 & 0 & 0 & V cldy & 0 & V cldy \\
\hline$"$ & 3 & 560 & $A$ & 0 & V cldy & 0 & V cldy \\
\hline$"$ & 3 & 560 & 0 & 0 & V cldy & 0 & V cldy \\
\hline
\end{tabular}

(a) Phase that is in the mixing zone before the other phase is introduced.

(b) Crys clr= crystal clear, Clr= clear, SI cldy= slightly cloudy, V cldy= very cloudy. 


\section{APPENDIX B. CALCULATIONS OF SOLVENT ENTRAINMENT DURING SOLVENT RECOVERY TEST}

Material balance was performed to calculate the values for $\mathrm{q}_{\mathrm{DW}}, \mathrm{q}_{\mathrm{CW}}$, and $\mathrm{q}_{\mathrm{BW}}$ (defined in Section 4), as shown in Figure B-1.

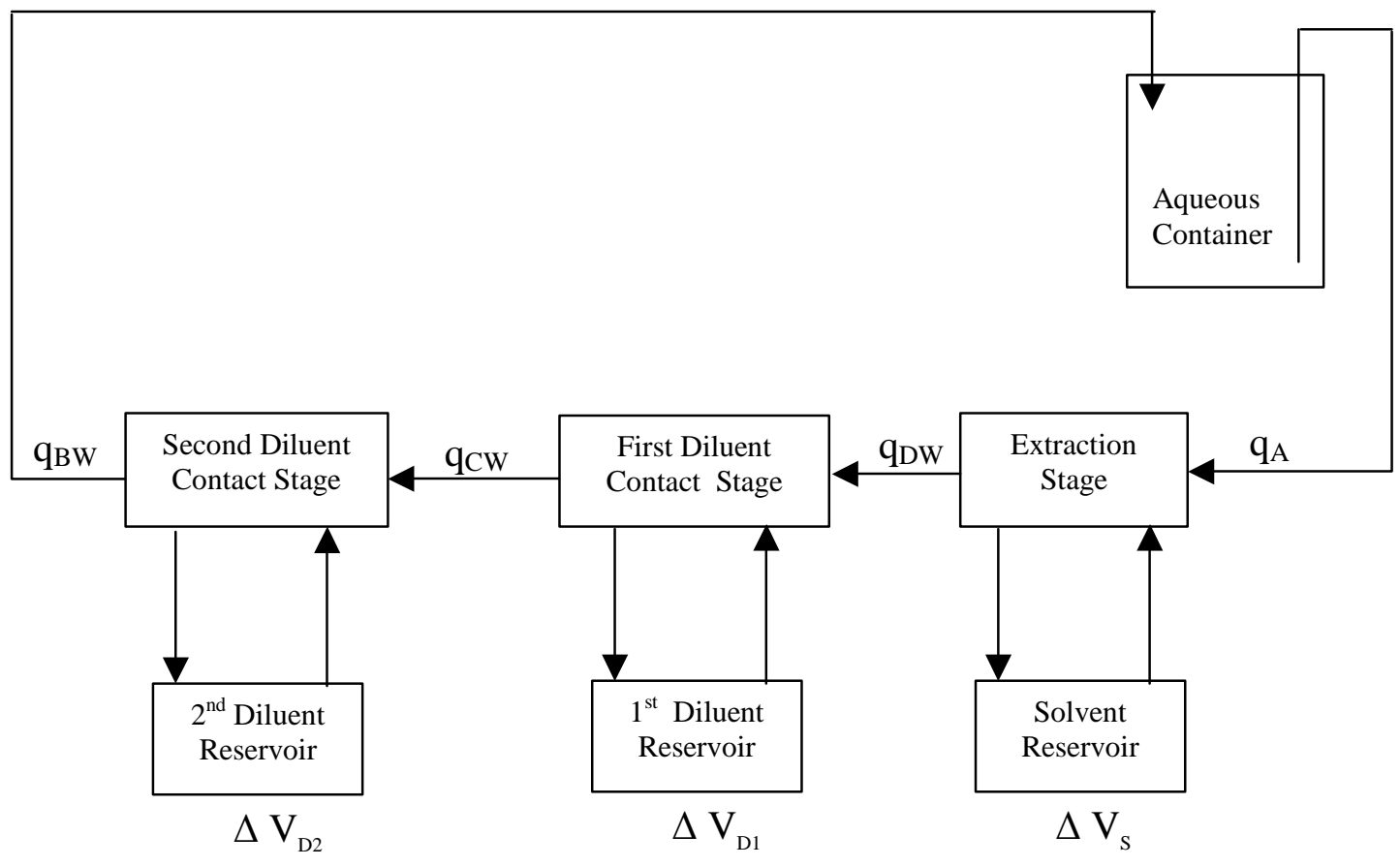

Figure B-1. Material Balance Calculations for Solvent Entrainment

Following are definitions for the symbols used in Figure B-1:

$\mathrm{q}_{\mathrm{A}}$ : $\quad$ Volume flow rate of organic entrained in aqueous phase entering the extraction stage $(\mathrm{L} / \mathrm{min})$

qDW: Volume flow rate of organic entrained in aqueous phase entering the first diluent contact stage (L/min)

qCw: Volume flow rate of organic entrained in aqueous phase entering the second diluent contact stage $(\mathrm{L} / \mathrm{min})$

qBw: Volume flow rate of organic entrained in aqueous phase exiting the second diluent contact stage (L/min)

$\Delta \mathrm{V}_{\mathrm{S}}: \quad$ Average rate of liquid volume change in solvent container $(\mathrm{L} / \mathrm{min})$

$\Delta \mathrm{V}_{\mathrm{D} 1}: \quad$ Average rate of liquid volume change in first diluent container $(\mathrm{L} / \mathrm{min})$

$\Delta \mathrm{V}_{\mathrm{D} 2}$ : Average rate of liquid volume change in second diluent container $(\mathrm{L} / \mathrm{min})$

Based on the material balance correlation

$$
\text { In = Out + Accumulation } \text {. }
$$


Assuming that the densities of the CSSX solvent and the first and second diluents are very close, we obtain:

$$
\begin{aligned}
& \mathrm{q}_{\mathrm{A}}=\mathrm{q}_{\mathrm{DW}}+\Delta \mathrm{V}_{\mathrm{S}} \\
& \mathrm{q}_{\mathrm{DW}}=\mathrm{q}_{\mathrm{CW}}+\Delta \mathrm{V}_{\mathrm{D} 1} \\
& \mathrm{q}_{\mathrm{CW}}=\mathrm{q}_{\mathrm{BW}}+\Delta \mathrm{V}_{\mathrm{D} 2}
\end{aligned}
$$

The aqueous container (a standard 1-L glass beaker) had a diameter of $10.3 \mathrm{~cm}$ with liquid height $=10 \mathrm{~cm}$ during the test. The aqueous flow was pumped out using a tube placed at the bottom of the reservoir. Following calculation steps similar to those in ARAFAT-2001, the superficial velocity (v) of a liquid layer moving downward in the beaker is

$$
\mathrm{v}=\frac{\text { Volumetric aqueous flow rate }}{\text { Beaker cross - sectional area }}
$$

or

$$
\mathrm{v}=\frac{1.67 \mathrm{E}-6 \mathrm{~m}^{3} / \mathrm{s}}{8.33 \mathrm{E}-3 \mathrm{~m}^{3}}=2 \mathrm{E}-4 \mathrm{~m} / \mathrm{s}
$$

Hence, assuming that the aqueous beaker is a perfect decanter, the minimum upward velocity of an entrained organic droplet to float to the beaker surface is $2 \mathrm{E}-4 \mathrm{~m} / \mathrm{s}$. Using Stoke's Law:

$$
\mathrm{v}=\frac{9.81\left(\mathrm{~d}^{2}\right)(\Delta \rho)}{18 \mu}
$$

where

$\mathrm{d}=$ droplet diameter, $\mathrm{m}$,

$\Delta \rho=$ difference in density of the two phases (aqueous and organic), $\mathrm{kg} / \mathrm{m}^{3}$, and $\mu=$ viscosity of the continuous phase, $\mathrm{Pa} \bullet \mathrm{s}$.

The densities of the aqueous simulant solution and organic diluent are about 1200 and 826 $\mathrm{kg} / \mathrm{m}^{3}$, respectively. The viscosity is assumed to be $0.0015 \mathrm{~Pa} \bullet \mathrm{s}$ for the simulant solution.

Substituting in Stoke's Law, the minimum droplet diameter that can escape from the downflowing aqueous phase (d) is $38.4 \mu \mathrm{m}$. Using the cumulative size distribution for entrained solvent in raffinate as reported in Appendix B of ARAFAT-2001, and assuming that the same size distribution can be used for diluent entrainment, the cumulative volume of droplets smaller than $38.4 \mu \mathrm{m}$ in the waste simulant, at medium mixing intensity (characteristic of the 4-cm contactor), is $1.6 \%$. This means that $\mathrm{q}_{\mathrm{A}}=0.016 \mathrm{q}_{\mathrm{BW}}$. However, the aqueous beaker does not perform as a perfect decanter due to the turbulence caused by the in-flowing liquid. Because we were unable to quantitatively estimate the effect of this turbulence, we used a $100 \%$ safety margin in estimating $\mathrm{q}_{\mathrm{A}}$. Hence,

$$
\mathrm{q}_{\mathrm{A}}=0.032 \mathrm{q}_{\mathrm{BW}}
$$


Solving Equations A-2 through A-4 and A-7 using the values for $\Delta \mathrm{V}_{\mathrm{S}}, \Delta \mathrm{V}_{\mathrm{D} 1}$, and $\Delta \mathrm{V}_{\mathrm{D} 2}$ reported in Table 5, the values for $\mathrm{q}_{\mathrm{DW}}, \mathrm{q}_{\mathrm{CW}}$, and $\mathrm{q}_{\mathrm{BW}}$ were calculated to be $1.46 \mathrm{E}-5,2.38 \mathrm{E}-4$, and 3.26E-4 L/min, respectively. 


\section{APPENDIX C. CALCULATIONS FOR SOLVENT RECOVERY USING A DECANTER TANK}

A cylindrical tank geometry is assumed with liquid height in the tank $(\mathrm{H})$ equal to the tank diameter (D) (see Figure C-1 below). The total tank volume is assumed to be 3,500 gallon $\left(13.25 \mathrm{~m}^{3}\right)$.

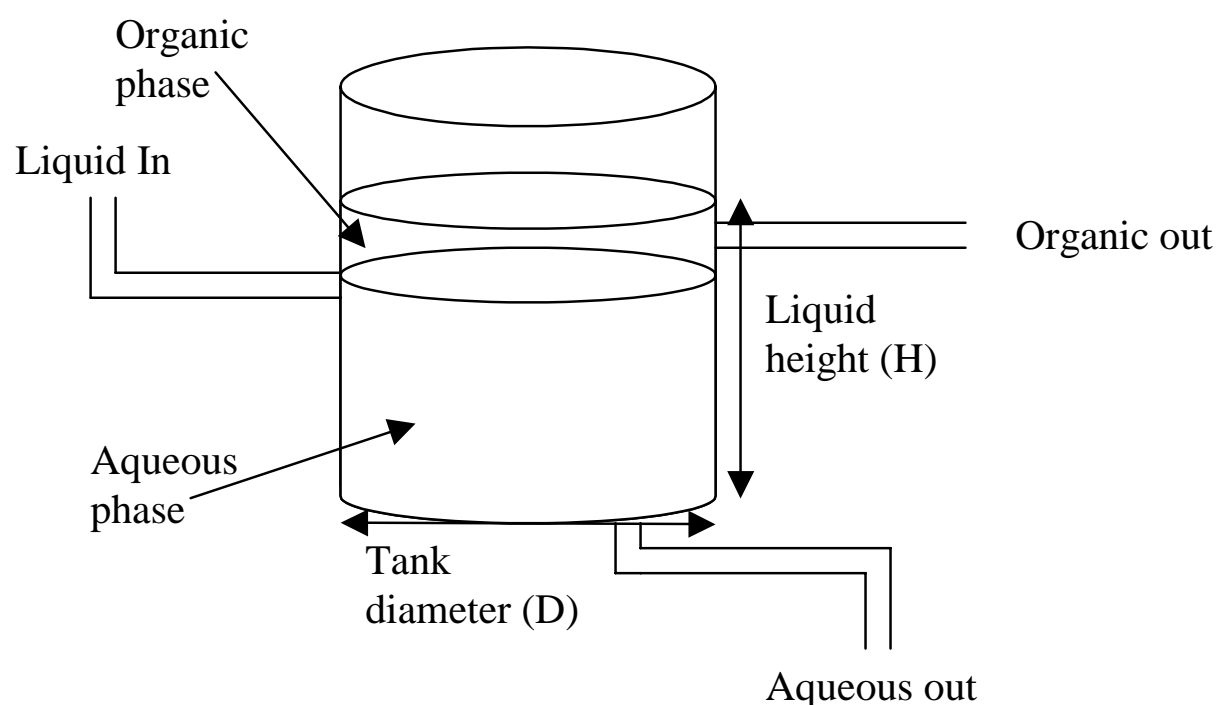

Figure C-1. Solvent Recovery in Decanter Tank

The decanter tank is assumed to be $80 \%$ full, i.e., liquid volume $=0.8 \times 13.25=10.6 \mathrm{~m}^{3}$. Therefore,

$$
\text { Liquid volume }(\mathrm{V})=\frac{\pi D^{2}}{4} H=\frac{\pi D^{3}}{4}=10.6 \mathrm{~m}^{3}
$$

Then, solving for $\mathrm{D}$ gives

$$
\mathrm{D}=\mathrm{H}=2.38 \mathrm{~m} \text {. }
$$

The total tank height $=2.38 / 0.8=2.98 \mathrm{~m}$.

The superficial velocity $\left(\mathrm{v}_{\mathrm{L}}\right)$ of the liquid moving downward in the tank is

$$
\mathrm{v}_{\mathrm{L}}=\frac{\text { Volumetric aqueous effluent flow rate }}{\text { Tank cross }- \text { sectional area }}
$$

For the raffinate tank, the superficial velocity $\left(\mathrm{v}_{\mathrm{L}, \mathrm{r}}\right)$ is 


$$
\mathrm{v}_{\mathrm{L}, \mathrm{r}}=\frac{1.35 \mathrm{E}-3 \mathrm{~m}^{3} / \mathrm{s}}{4.45 \mathrm{~m}^{2}}=3.03 \mathrm{E}-4 \mathrm{~m} / \mathrm{s}
$$

For the strip solution tank, the superficial velocity $\left(\mathrm{v}_{\mathrm{L}, \mathrm{S}}\right)$ is

$$
\mathrm{v}_{\mathrm{L}, \mathrm{s}}=\frac{8.4 \mathrm{E}-5 \mathrm{~m}^{3} / \mathrm{s}}{4.45 \mathrm{~m}^{2}}=1.89 \mathrm{E}-5 \mathrm{~m} / \mathrm{s}
$$

Hence, the minimum upward velocity of a droplet $\left(\mathrm{v}_{\mathrm{d}, \mathrm{r}}\right)$ to be decanted in the raffinate tank is $3.03 \mathrm{E}-4 \mathrm{~m} / \mathrm{s}$, and that of a droplet in the strip solution tank $\left(\mathrm{v}_{\mathrm{d}, \mathrm{s}}\right)$ is $1.89 \mathrm{E}-5 \mathrm{~m} / \mathrm{s}$.

Using Stoke's Law:

$$
\mathrm{v}_{\mathrm{d}}=\frac{9.81\left(\mathrm{~d}^{2}\right)(\Delta \rho)}{18 \mu}
$$

where

$\mathrm{v}_{\mathrm{d}}=$ upward droplet velocity, $\mathrm{m} / \mathrm{s}$, $\mathrm{d}=$ droplet diameter, $\mathrm{m}$, $\Delta \rho=$ difference in density of the two phases (aqueous and organic), $\mathrm{kg} / \mathrm{m}^{3}$, and $\mu=$ viscosity of the continuous phase, $\mathrm{Pa} \bullet \mathrm{s}$.

The densities of the raffinate solution, strip solution, and solvent are about 1200, 1000, and 826 $\mathrm{kg} / \mathrm{m}^{3}$, respectively. The viscosity is assumed to be $0.0015 \mathrm{~Pa} \bullet \mathrm{s}$ for both aqueous solutions.

Substituting in Stoke's Law for the aqueous raffinate, the minimum droplet diameter that can escape from the down-flowing aqueous phase $\left(d_{r}\right)$ is $47 \mu \mathrm{m}$. Similarly, for the aqueous strip effluent, the minimum droplet diameter $\left(\mathrm{d}_{\mathrm{s}}\right)$ is $17 \mu \mathrm{m}$.

Using the cumulative size distribution in ARAFAT-2001, the cumulative volume of droplets smaller than $47 \mu \mathrm{m}$ in the raffinate solution, at high mixing intensity (expected in the plant-scale contactors) is $72.5 \%$. Therefore, $27.5 \%$ of the entrained solvent will be recovered. For the strip solution at medium mixing intensity, $0 \%$ of the droplets are of size $17 \mu \mathrm{m}$ or less. Hence, $100 \%$ of the entrained solvent will be recovered. 


\section{APPENDIX D. CALCULATIONS FOR SOLVENT RECOVERY USING A CENTRIFUGE}

The following calculations are made for a Westfalia Disc bowl centrifuge (model TA 50). The centrifuge has a bowl diameter of $60 \mathrm{~cm}$ with a liquid capacity of $20 \mathrm{~L}$ in the separation zone. The bowl diameter is divided into an inner feeding zone with a $10-\mathrm{cm}$ radius and an external separation zone with a $20-\mathrm{cm}$ radius. The centrifuge has a maximum speed of about 7,000 rpm. Assuming a 6,000-rpm speed, then the rotational speed $(\omega)$ is

$$
\begin{aligned}
\omega & =2 \pi(\mathrm{rpm}) / 60 \\
& =2 \times 3.14 \times 6000 / 60=628 \mathrm{rad} / \mathrm{s}
\end{aligned}
$$

Assuming an average separation zone radius (r) of $20 \mathrm{~cm}$ from the center of the bowl, the average centrifugal acceleration (a) is

$$
\begin{aligned}
\mathrm{a} & =\mathrm{r} \omega^{2} \\
& =0.2(628)^{2}=78,900 \mathrm{~m} / \mathrm{s}^{2}
\end{aligned}
$$

The residence time $(\mathrm{t})$ of liquid moving through the centrifuge is defined as

$$
\mathrm{t}=\frac{\text { Liquid volume in separation zone }}{\text { Flow rate }}
$$

For the raffinate

$$
\mathrm{t}_{\mathrm{r}}=\frac{20 \mathrm{~L}}{81(\mathrm{~L} / \mathrm{min}) \times 1 / 60(\mathrm{~min} / \mathrm{s})}=15 \mathrm{~s} .
$$

For the strip

$$
\mathrm{t}_{\mathrm{s}}=\frac{20 \mathrm{~L}}{0.05(\mathrm{~L} / \mathrm{min}) \times 1 / 60(\mathrm{~min} / \mathrm{s})}=24,000 \mathrm{~s} .
$$

Hence, the minimum velocity of a solvent droplet $\left(\mathrm{V}_{\mathrm{d}, \mathrm{r}}\right)$ to be separated from the raffinate solution is

$$
\begin{aligned}
& \mathrm{V}_{\mathrm{d}, \mathrm{r}}=\frac{\text { Radius of separation zone }}{\text { Residence time }} \\
& \mathrm{V}_{\mathrm{d}, \mathrm{r}}=0.2 / 15=0.013 \mathrm{~m} / \mathrm{s}
\end{aligned}
$$

Similarly, the minimum velocity of a solvent droplet $\left(\mathrm{V}_{\mathrm{d}, \mathrm{s}}\right)$ to be separated from the strip solution is

$$
\mathrm{V}_{\mathrm{d}, \mathrm{s}}=0.2 / 24,000=8.3 \mathrm{E}-6 \mathrm{~m} / \mathrm{s} .
$$


Using Stoke's law,

$$
\mathrm{V}_{\mathrm{d}}=\frac{\mathrm{a}\left(\mathrm{d}^{2}\right)(\Delta \rho)}{18 \mu} \text { (see definitions and values in Appendix C). }
$$

Substituting in Stoke's Law for the aqueous raffinate, the minimum droplet diameter that can escape from the aqueous phase leaving the centrifuge $\left(\mathrm{d}_{\mathrm{r}}\right)$ is $3.5 \mu \mathrm{m}$. Similarly, for the aqueous strip effluent, the minimum droplet diameter $\left(\mathrm{d}_{\mathrm{s}}\right)$ is $0.13 \mu \mathrm{m}$.

Using the cumulative size distribution in ARAFAT-2001, the cumulative volume of droplets smaller than $3.5 \mu \mathrm{m}$ in the raffinate solution, at high mixing intensity (expected in the plant-scale contactors) is $10 \%$. Therefore, $90 \%$ of the entrained solvent will be recovered. For the strip solution at medium mixing intensity, $0 \%$ of the droplets are of size $0.13 \mu \mathrm{m}$ or less. Hence, $100 \%$ of the entrained solvent will be recovered. 


\section{APPENDIX E. CALCULATIONS FOR SOLVENT RECOVERY USING DILUENT CONTACT IN CENTRIFUGAL CONTACTOR}

In this method, two centrifugal contactors are used to contact the aqueous flow with diluent (Isopar ${ }^{\circledR} \mathrm{L}$ ) in order to recover both entrained and dissolved solvent in the aqueous flow. It was found (Section 4.1) that the average efficiency for the solvent recovery stages is about 94.5\%. Entrainment levels of up to $0.3 \%$ diluent in the raffinate, which is higher than the previously measured level of $121 \mathrm{ppm}$ (or $0.012 \%$ ) for solvent in the raffinate [ARAFAT-2001], was observed in the solvent recovery stages, as discussed in Section 5.1. These levels are well within the acceptable limit of a hydraulic-problem-free operation, which is $1 \%$. Nonetheless, for plant operation calculations, we will assume the average entrainment value, $121 \mathrm{ppm}$, in our calculations. This entrainment value, which is anticipated in the plant facility when no hydraulic process upsets are present, was found to be independent of mixing intensity or aqueous flow type (raffinate or strip) [ARAFAT-2001]. We also assumed that $30 \mathrm{~L}$ of diluent will be used in each contact stage and that used diluent will be replaced, all at once, with fresh diluent every 24 hours. The model detailed in Section 3 was used to calculate the amounts (in moles per 24 hours) of BOBCalixC6 and modifier that are lost in the aqueous phase after being contacted with the diluent. As shown below in the Excel Spreadsheet calculations, these amounts were found to be 5.24E-3 and $0.26 \mathrm{~mol} / \mathrm{day}$ of BOBCalixC6 and modifier, respectively. The following information is provided for interpreting Tables E-1 and E-2.

\section{Definition of Symbols:}

$\mathrm{V}_{1}: \quad$ Volume of diluent in the first diluent-contact stage (L)

$\mathrm{V}_{2}$ : $\quad$ Volume of diluent in the second diluent-contact stage (L)

A: $\quad$ A defined value, see Equation 7 in Section 3

B: $\quad$ A defined value, see Equation 8 in Section 3

$\mathrm{C}_{1}$ : $\quad$ Concentration of solvent component (BOBCalixC6 or modifier) in entrained diluent exiting first diluent contact stage $(\underline{\mathrm{M}})$

$\mathrm{C}_{\mathrm{T} 1}$ : Concentration of solvent component (BOBCalixC6 or modifier) in the first diluent reservoir $(\underline{\mathrm{M}})$

$\mathrm{C}_{\mathrm{T} 2}$ : Concentration of solvent component (BOBCalixC6 or modifier) in the second diluent reservoir $(\underline{\mathrm{M}})$

$\mathrm{M}_{\mathrm{E}}$ : Moles of unrecovered extractant, $\mathrm{M}_{\mathrm{E}}=\mathrm{C}_{\mathrm{T} 2} * \mathrm{q}_{\mathrm{BW}} * \Delta \mathrm{t}$ (where $\mathrm{C}_{\mathrm{T} 2}$ is BOBCalixC6 concentration) (mole).

$\mathrm{M}_{\mathrm{M}}$ : Moles of unrecovered modifier, $\mathrm{M}_{\mathrm{M}}=\mathrm{C}_{\mathrm{T} 2} * \mathrm{q}_{\mathrm{BW}} * \Delta \mathrm{t}$ (where $\mathrm{C}_{\mathrm{T} 2}$ is modifier concentration) (mole).

\section{Constant Values (Tables E-1 and E-2):}

$\mathrm{E}_{\mathrm{a}}: \quad 0.945$

qDw: $9.8 \mathrm{E}-3 \mathrm{~L} / \mathrm{min}$ (based on $121 \mathrm{ppm}$ entrainment)

qCw: $9.8 \mathrm{E}-3 \mathrm{~L} / \mathrm{min}$ (based on $121 \mathrm{ppm}$ entrainment)

$\mathrm{q}_{\mathrm{BW}}$ : $9.8 \mathrm{E}-3 \mathrm{~L} / \mathrm{min}$ (based on $121 \mathrm{ppm}$ entrainment) 
Initial Values (Table E-1):

$\mathrm{C}_{\mathrm{o}}: \quad 0.01 \mathrm{~mol}$ BOBCalixC6/L

$\mathrm{C}_{\mathrm{T} 1,0}: 0$ mol BOBCalixC6/L

Initial Values (Table E-2):

$\mathrm{C}_{\mathrm{o} \text {, modifier }}: \quad 0.5$ modifier $/ \mathrm{L}$

$\mathrm{C}_{\mathrm{T} 1, \mathrm{o} \text {, modifier: }} 0 \mathrm{~mol}$ modifier/L 
Table E-1. Moles of BOBCalixC6 Not Recovered by Diluent Contact

\begin{tabular}{|c|c|c|c|c|c|c|c|c|}
\hline Time & $\begin{array}{c}\text { Average } \mathrm{K} \\
\text { (L) }\end{array}$ & $\begin{array}{c}\text { Average } \mathrm{V}_{2} \\
(\mathrm{~L})\end{array}$ & A & B & $\mathrm{C}_{1}(\underline{\mathrm{M}})$ & $\mathrm{C}_{\mathrm{T}_{1}}(\underline{\mathrm{M}})$ & $\mathrm{C}_{\mathrm{T} 2}(\underline{\mathrm{M}})$ & $\mathrm{M}_{\mathrm{E}}(\mathrm{mol})$ \\
\hline 0 & 30 & 30 & 3.09E-06 & 3.09E-04 & 5.50E-04 & $0 \mathrm{E}+00$ & 0 & 0 \\
\hline 29 & 30 & 30 & 3.09E-06 & 3.09E-04 & 6.34E-04 & 8.85E-05 & 5.58E-06 & $1.58 \mathrm{E}-06$ \\
\hline 58 & 30 & 30 & 3.09E-06 & 3.09E-04 & 7.17E-04 & 1.76E-04 & 1.19E-05 & 3.34E-06 \\
\hline 86 & 30 & 30 & 3.09E-06 & 3.09E-04 & 7.99E-04 & 2.63E-04 & 1.88E-05 & $5.30 \mathrm{E}-06$ \\
\hline 115 & 30 & 30 & 3.09E-06 & 3.09E-04 & 8.80E-04 & 3.49E-04 & 2.64E-05 & $7.45 \mathrm{E}-06$ \\
\hline 144 & 30 & 30 & 3.09E-06 & 3.09E-04 & $9.61 \mathrm{E}-04$ & 4.35E-04 & $3.46 \mathrm{E}-05$ & $9.77 \mathrm{E}-06$ \\
\hline 173 & 30 & 30 & $3.09 E-06$ & $3.09 E-04$ & $1.04 \mathrm{E}-03$ & 5.20E-04 & 4.35E-05 & 1.23E-05 \\
\hline 202 & 30 & 30 & $3.09 E-06$ & $3.09 E-04$ & $1.12 \mathrm{E}-03$ & $6.03 E-04$ & 5.30E-05 & $1.50 \mathrm{E}-05$ \\
\hline 230 & 30 & 30 & $3.09 E-06$ & $3.09 E-04$ & $1.20 \mathrm{E}-03$ & 6.87E-04 & $6.31 \mathrm{E}-05$ & $1.78 \mathrm{E}-05$ \\
\hline 259 & 30 & 30 & $3.09 E-06$ & $3.09 \mathrm{E}-04$ & $1.28 \mathrm{E}-03$ & 7.69E-04 & 7.38E-05 & $2.08 \mathrm{E}-05$ \\
\hline 288 & 30 & 30 & $3.09 E-06$ & $3.09 \mathrm{E}-04$ & $1.35 \mathrm{E}-03$ & $8.51 \mathrm{E}-04$ & $8.50 \mathrm{E}-05$ & $2.40 \mathrm{E}-05$ \\
\hline 317 & 30 & 30 & $3.09 E-06$ & $3.09 \mathrm{E}-04$ & $1.43 \mathrm{E}-03$ & 9.32E-04 & 9.69E-05 & $2.74 \mathrm{E}-05$ \\
\hline 346 & 30 & 30 & $3.09 E-06$ & $3.09 \mathrm{E}-04$ & $1.51 \mathrm{E}-03$ & $1.01 \mathrm{E}-03$ & $1.09 \mathrm{E}-04$ & $3.09 \mathrm{E}-05$ \\
\hline 374 & 30 & 30 & $3.09 E-06$ & $3.09 \mathrm{E}-04$ & $1.58 \mathrm{E}-03$ & 1.09E-03 & $1.22 \mathrm{E}-04$ & $3.45 \mathrm{E}-05$ \\
\hline 403 & 30 & 30 & 3.09E-06 & 3.09E-04 & 1.66E-03 & 1.17E-03 & 1.36E-04 & 3.83E-05 \\
\hline 432 & 30 & 30 & 3.09E-06 & 3.09E-04 & $1.73 \mathrm{E}-03$ & $1.25 \mathrm{E}-03$ & $1.50 \mathrm{E}-04$ & $4.23 \mathrm{E}-05$ \\
\hline 461 & 30 & 30 & 3.09E-06 & 3.09E-04 & $1.80 \mathrm{E}-03$ & 1.33E-03 & 1.64E-04 & $4.64 \mathrm{E}-05$ \\
\hline 490 & 30 & 30 & $3.09 \mathrm{E}-06$ & 3.09E-04 & $1.88 \mathrm{E}-03$ & $1.40 \mathrm{E}-03$ & $1.80 \mathrm{E}-04$ & $5.07 \mathrm{E}-05$ \\
\hline 518 & 30 & 30 & 3.09E-06 & 3.09E-04 & $1.95 \mathrm{E}-03$ & $1.48 \mathrm{E}-03$ & 1.95E-04 & $5.51 \mathrm{E}-05$ \\
\hline 547 & 30 & 30 & $3.09 \mathrm{E}-06$ & 3.09E-04 & $2.02 \mathrm{E}-03$ & $1.55 \mathrm{E}-03$ & $2.11 \mathrm{E}-04$ & 5.96E-05 \\
\hline 576 & 30 & 30 & 3.09E-06 & 3.09E-04 & $2.09 \mathrm{E}-03$ & 1.63E-03 & $2.28 \mathrm{E}-04$ & $6.43 \mathrm{E}-05$ \\
\hline 605 & 30 & 30 & 3.09E-06 & 3.09E-04 & $2.16 \mathrm{E}-03$ & $1.70 \mathrm{E}-03$ & $2.45 \mathrm{E}-04$ & $6.91 \mathrm{E}-05$ \\
\hline 634 & 30 & 30 & $3.09 E-06$ & $3.09 \mathrm{E}-04$ & $2.23 \mathrm{E}-03$ & $1.78 \mathrm{E}-03$ & 2.62E-04 & $7.40 \mathrm{E}-05$ \\
\hline 662 & 30 & 30 & 3.09E-06 & 3.09E-04 & $2.30 \mathrm{E}-03$ & $1.85 \mathrm{E}-03$ & 2.80E-04 & $7.91 \mathrm{E}-05$ \\
\hline 691 & 30 & 30 & $3.09 E-06$ & $3.09 \mathrm{E}-04$ & 2.37E-03 & $1.92 \mathrm{E}-03$ & $2.99 \mathrm{E}-04$ & 8.43E-05 \\
\hline 720 & 30 & 30 & $3.09 E-06$ & 3.09E-04 & $2.43 \mathrm{E}-03$ & 1.99E-03 & $3.17 \mathrm{E}-04$ & 8.96E-05 \\
\hline 749 & 30 & 30 & $3.09 E-06$ & $3.09 \mathrm{E}-04$ & $2.50 \mathrm{E}-03$ & 2.06E-03 & 3.37E-04 & $9.50 \mathrm{E}-05$ \\
\hline 778 & 30 & 30 & $3.09 E-06$ & 3.09E-04 & 2.57E-03 & $2.13 \mathrm{E}-03$ & $3.56 \mathrm{E}-04$ & $1.01 \mathrm{E}-04$ \\
\hline 806 & 30 & 30 & $3.09 E-06$ & 3.09E-04 & 2.63E-03 & $2.20 \mathrm{E}-03$ & $3.76 \mathrm{E}-04$ & 1.06E-04 \\
\hline 835 & 30 & 30 & $3.09 E-06$ & 3.09E-04 & 2.70E-03 & 2.27E-03 & 3.97E-04 & $1.12 \mathrm{E}-04$ \\
\hline 864 & 30 & 30 & $3.09 \mathrm{E}-06$ & $3.09 \mathrm{E}-04$ & $2.76 \mathrm{E}-03$ & $2.34 \mathrm{E}-03$ & $4.18 \mathrm{E}-04$ & 1.18E-04 \\
\hline 893 & 30 & 30 & $3.09 \mathrm{E}-06$ & $3.09 \mathrm{E}-04$ & $2.83 \mathrm{E}-03$ & $2.41 \mathrm{E}-03$ & 4.39E-04 & $1.24 \mathrm{E}-04$ \\
\hline 922 & 30 & 30 & $3.09 \mathrm{E}-06$ & $3.09 \mathrm{E}-04$ & $2.89 \mathrm{E}-03$ & $2.48 \mathrm{E}-03$ & $4.60 \mathrm{E}-04$ & 1.30E-04 \\
\hline 950 & 30 & 30 & $3.09 \mathrm{E}-06$ & 3.09E-04 & $2.95 \mathrm{E}-03$ & $2.54 \mathrm{E}-03$ & 4.82E-04 & 1.36E-04 \\
\hline 979 & 30 & 30 & $3.09 \mathrm{E}-06$ & $3.09 \mathrm{E}-04$ & $3.02 \mathrm{E}-03$ & $2.61 \mathrm{E}-03$ & $5.05 \mathrm{E}-04$ & $1.42 \mathrm{E}-04$ \\
\hline 1008 & 30 & 30 & $3.09 \mathrm{E}-06$ & $3.09 \mathrm{E}-04$ & $3.08 \mathrm{E}-03$ & 2.67E-03 & $5.27 \mathrm{E}-04$ & $1.49 \mathrm{E}-04$ \\
\hline 1037 & 30 & 30 & $3.09 \mathrm{E}-06$ & 3.09E-04 & $3.14 \mathrm{E}-03$ & $2.74 \mathrm{E}-03$ & $5.50 \mathrm{E}-04$ & $1.55 \mathrm{E}-04$ \\
\hline 1066 & 30 & 30 & $3.09 \mathrm{E}-06$ & $3.09 \mathrm{E}-04$ & $3.20 \mathrm{E}-03$ & $2.80 \mathrm{E}-03$ & $5.74 \mathrm{E}-04$ & $1.62 \mathrm{E}-04$ \\
\hline 1094 & 30 & 30 & 3.09E-06 & 3.09E-04 & $3.26 \mathrm{E}-03$ & 2.87E-03 & 5.97E-04 & $1.69 \mathrm{E}-04$ \\
\hline 1123 & 30 & 30 & 3.09E-06 & 3.09E-04 & 3.32E-03 & $2.93 \mathrm{E}-03$ & $6.21 \mathrm{E}-04$ & $1.75 \mathrm{E}-04$ \\
\hline 1152 & 30 & 30 & $3.09 E-06$ & $3.09 \mathrm{E}-04$ & $3.38 \mathrm{E}-03$ & 2.99E-03 & $6.46 \mathrm{E}-04$ & $1.82 \mathrm{E}-04$ \\
\hline 1181 & 30 & 30 & $3.09 E-06$ & $3.09 \mathrm{E}-04$ & $3.44 \mathrm{E}-03$ & $3.05 \mathrm{E}-03$ & $6.70 \mathrm{E}-04$ & $1.89 \mathrm{E}-04$ \\
\hline 1210 & 30 & 30 & $3.09 E-06$ & $3.09 \mathrm{E}-04$ & $3.49 \mathrm{E}-03$ & $3.12 \mathrm{E}-03$ & $6.95 \mathrm{E}-04$ & $1.96 \mathrm{E}-04$ \\
\hline 1238 & 30 & 30 & $3.09 E-06$ & $3.09 \mathrm{E}-04$ & $3.55 \mathrm{E}-03$ & $3.18 \mathrm{E}-03$ & $7.20 \mathrm{E}-04$ & 2.03E-04 \\
\hline 1267 & 30 & 30 & $3.09 E-06$ & $3.09 \mathrm{E}-04$ & $3.61 \mathrm{E}-03$ & $3.24 \mathrm{E}-03$ & 7.46E-04 & $2.11 \mathrm{E}-04$ \\
\hline 1296 & 30 & 30 & $3.09 E-06$ & $3.09 \mathrm{E}-04$ & 3.67E-03 & 3.30E-03 & 7.72E-04 & $2.18 \mathrm{E}-04$ \\
\hline 1325 & 30 & 30 & $3.09 E-06$ & $3.09 \mathrm{E}-04$ & $3.72 \mathrm{E}-03$ & 3.36E-03 & 7.98E-04 & $2.25 \mathrm{E}-04$ \\
\hline 1354 & 30 & 30 & $3.09 E-06$ & $3.09 E-04$ & $3.78 \mathrm{E}-03$ & $3.42 \mathrm{E}-03$ & 8.24E-04 & 2.33E-04 \\
\hline 1382 & 30 & 30 & $3.09 E-06$ & $3.09 E-04$ & $3.83 \mathrm{E}-03$ & $3.47 E-03$ & $8.50 \mathrm{E}-04$ & $2.40 \mathrm{E}-04$ \\
\hline 1411 & 30 & 30 & $3.09 E-06$ & $3.09 E-04$ & $3.89 \mathrm{E}-03$ & $3.53 E-03$ & 8.77E-04 & $2.48 \mathrm{E}-04$ \\
\hline 1440 & 30 & 30 & $3.09 \mathrm{E}-06$ & $3.09 \mathrm{E}-04$ & $3.94 \mathrm{E}-03$ & $3.59 E-03$ & $9.04 \mathrm{E}-04$ & $2.55 \mathrm{E}-04$ \\
\hline
\end{tabular}

Total BOBCalixC6 in $24 \mathrm{hr}$, moles = $5.24 \mathrm{E}-03$ 
Table E-2. Moles of Modifier Not Recovered by Diluent Contact

\begin{tabular}{|c|c|c|c|c|c|c|c|c|}
\hline Time & $\begin{array}{c}\text { Average } V_{1} \\
(L)\end{array}$ & $\begin{array}{c}\text { Average } V_{2} \\
(L)\end{array}$ & A & B & $\mathrm{C}_{1}(\underline{\mathrm{M}})$ & $\mathrm{C}_{\mathrm{T} 1}(\underline{\mathrm{M}})$ & $\mathrm{C}_{\mathrm{T} 2}(\underline{\mathrm{M}})$ & $\mathrm{M}_{\mathrm{M}}(\mathrm{mol})$ \\
\hline 0 & 30 & 30 & $1.54 \mathrm{E}-04$ & $3.09 \mathrm{E}-04$ & 2.75E-02 & $0.00 \mathrm{E}+00$ & 0 & 0 \\
\hline 29 & 30 & 30 & 1.54E-04 & 3.09E-04 & 3.17E-02 & 4.43E-03 & $2.79 \mathrm{E}-04$ & $7.88 \mathrm{E}-05$ \\
\hline 58 & 30 & 30 & $1.54 \mathrm{E}-04$ & $3.09 \mathrm{E}-04$ & 3.58E-02 & 8.81E-03 & 5.93E-04 & 1.67E-04 \\
\hline 86 & 30 & 30 & $1.54 \mathrm{E}-04$ & $3.09 E-04$ & 3.99E-02 & 1.32E-02 & 9.39E-04 & 2.65E-04 \\
\hline 115 & 30 & 30 & $1.54 \mathrm{E}-04$ & $3.09 E-04$ & 4.40E-02 & 1.75E-02 & 1.32E-03 & 3.72E-04 \\
\hline 144 & 30 & 30 & $1.54 \mathrm{E}-04$ & 3.09E-04 & 4.80E-02 & 2.17E-02 & 1.73E-03 & 4.89E-04 \\
\hline 173 & 30 & 30 & $1.54 \mathrm{E}-04$ & $3.09 E-04$ & $5.20 \mathrm{E}-02$ & 2.60E-02 & 2.17E-03 & 6.14E-04 \\
\hline 202 & 30 & 30 & $1.54 \mathrm{E}-04$ & $3.09 E-04$ & $5.60 \mathrm{E}-02$ & 3.02E-02 & 2.65E-03 & 7.48E-04 \\
\hline 230 & 30 & 30 & $1.54 \mathrm{E}-04$ & 3.09E-04 & 5.99E-02 & $3.43 \mathrm{E}-02$ & $3.15 \mathrm{E}-03$ & $8.90 \mathrm{E}-04$ \\
\hline 259 & 30 & 30 & $1.54 \mathrm{E}-04$ & 3.09E-04 & 6.38E-02 & 3.85E-02 & 3.69E-03 & 1.04E-03 \\
\hline 288 & 30 & 30 & $1.54 \mathrm{E}-04$ & 3.09E-04 & 6.77E-02 & 4.25E-02 & $4.25 \mathrm{E}-03$ & $1.20 \mathrm{E}-03$ \\
\hline 317 & 30 & 30 & $1.54 \mathrm{E}-04$ & $3.09 E-04$ & 7.15E-02 & 4.66E-02 & 4.85E-03 & 1.37E-03 \\
\hline 346 & 30 & 30 & $1.54 \mathrm{E}-04$ & $3.09 E-04$ & 7.53E-02 & 5.06E-02 & 5.47E-03 & 1.54E-03 \\
\hline 374 & 30 & 30 & $1.54 \mathrm{E}-04$ & 3.09E-04 & 7.91E-02 & 5.46E-02 & 6.12E-03 & 1.73E-03 \\
\hline 403 & 30 & 30 & $1.54 \mathrm{E}-04$ & $3.09 \mathrm{E}-04$ & 8.28E-02 & 5.85E-02 & 6.79E-03 & $1.92 \mathrm{E}-03$ \\
\hline 432 & 30 & 30 & $1.54 \mathrm{E}-04$ & $3.09 \mathrm{E}-04$ & 8.65E-02 & $6.24 \mathrm{E}-02$ & 7.49E-03 & $2.12 \mathrm{E}-03$ \\
\hline 461 & 30 & 30 & $1.54 \mathrm{E}-04$ & $3.09 E-04$ & $9.02 \mathrm{E}-02$ & 6.63E-02 & $8.22 \mathrm{E}-03$ & $2.32 \mathrm{E}-03$ \\
\hline 490 & 30 & 30 & $1.54 \mathrm{E}-04$ & 3.09E-04 & $9.38 \mathrm{E}-02$ & 7.01E-02 & 8.98E-03 & $2.53 \mathrm{E}-03$ \\
\hline 518 & 30 & 30 & $1.54 \mathrm{E}-04$ & 3.09E-04 & $9.74 \mathrm{E}-02$ & 7.39E-02 & $9.76 \mathrm{E}-03$ & $2.75 \mathrm{E}-03$ \\
\hline 547 & 30 & 30 & $1.54 \mathrm{E}-04$ & $3.09 \mathrm{E}-04$ & $1.01 \mathrm{E}-01$ & 7.77E-02 & $1.06 \mathrm{E}-02$ & $2.98 \mathrm{E}-03$ \\
\hline 576 & 30 & 30 & $1.54 \mathrm{E}-04$ & 3.09E-04 & $1.04 \mathrm{E}-01$ & 8.15E-02 & 1.14E-02 & $3.21 \mathrm{E}-03$ \\
\hline 605 & 30 & 30 & $1.54 \mathrm{E}-04$ & 3.09E-04 & $1.08 \mathrm{E}-01$ & 8.52E-02 & $1.22 \mathrm{E}-02$ & $3.45 \mathrm{E}-03$ \\
\hline 634 & 30 & 30 & $1.54 \mathrm{E}-04$ & $3.09 E-04$ & $1.11 \mathrm{E}-01$ & 8.88E-02 & $1.31 \mathrm{E}-02$ & 3.70E-03 \\
\hline 662 & 30 & 30 & $1.54 \mathrm{E}-04$ & $3.09 E-04$ & 1.15E-01 & $9.25 \mathrm{E}-02$ & 1.40E-02 & 3.95E-03 \\
\hline 691 & 30 & 30 & $1.54 \mathrm{E}-04$ & $3.09 \mathrm{E}-04$ & 1.18E-01 & 9.61E-02 & 1.49E-02 & $4.21 \mathrm{E}-03$ \\
\hline 720 & 30 & 30 & $1.54 \mathrm{E}-04$ & 3.09E-04 & 1.22E-01 & 9.97E-02 & $1.59 \mathrm{E}-02$ & 4.48E-03 \\
\hline 749 & 30 & 30 & $1.54 \mathrm{E}-04$ & 3.09E-04 & $1.25 \mathrm{E}-01$ & $1.03 E-01$ & $1.68 \mathrm{E}-02$ & 4.75E-03 \\
\hline 778 & 30 & 30 & $1.54 \mathrm{E}-04$ & $3.09 \mathrm{E}-04$ & $1.28 \mathrm{E}-01$ & 1.07E-01 & 1.78E-02 & 5.03E-03 \\
\hline 806 & 30 & 30 & $1.54 \mathrm{E}-04$ & $3.09 E-04$ & 1.32E-01 & 1.10E-01 & 1.88E-02 & 5.31E-03 \\
\hline 835 & 30 & 30 & $1.54 \mathrm{E}-04$ & $3.09 \mathrm{E}-04$ & $1.35 \mathrm{E}-01$ & 1.14E-01 & 1.98E-02 & $5.60 \mathrm{E}-03$ \\
\hline 864 & 30 & 30 & $1.54 \mathrm{E}-04$ & $3.09 \mathrm{E}-04$ & $1.38 \mathrm{E}-01$ & 1.17E-01 & 2.09E-02 & 5.89E-03 \\
\hline 893 & 30 & 30 & $1.54 \mathrm{E}-04$ & 3.09E-04 & $1.41 \mathrm{E}-01$ & $1.20 \mathrm{E}-01$ & 2.19E-02 & $6.19 \mathrm{E}-03$ \\
\hline 922 & 30 & 30 & $1.54 \mathrm{E}-04$ & 3.09E-04 & 1.45E-01 & $1.24 \mathrm{E}-01$ & 2.30E-02 & $6.50 \mathrm{E}-03$ \\
\hline 950 & 30 & 30 & $1.54 \mathrm{E}-04$ & $3.09 E-04$ & 1.48E-01 & 1.27E-01 & $2.41 \mathrm{E}-02$ & 6.81E-03 \\
\hline 979 & 30 & 30 & $1.54 \mathrm{E}-04$ & 3.09E-04 & $1.51 \mathrm{E}-01$ & 1.30E-01 & 2.52E-02 & 7.12E-03 \\
\hline 1008 & 30 & 30 & $1.54 \mathrm{E}-04$ & 3.09E-04 & $1.54 \mathrm{E}-01$ & $1.34 \mathrm{E}-01$ & 2.64E-02 & $7.44 \mathrm{E}-03$ \\
\hline 1037 & 30 & 30 & $1.54 \mathrm{E}-04$ & $3.09 \mathrm{E}-04$ & $1.57 \mathrm{E}-01$ & 1.37E-01 & $2.75 \mathrm{E}-02$ & 7.77E-03 \\
\hline 1066 & 30 & 30 & $1.54 \mathrm{E}-04$ & 3.09E-04 & $1.60 \mathrm{E}-01$ & $1.40 \mathrm{E}-01$ & 2.87E-02 & $8.10 \mathrm{E}-03$ \\
\hline 1094 & 30 & 30 & $1.54 \mathrm{E}-04$ & $3.09 \mathrm{E}-04$ & 1.63E-01 & $1.43 \mathrm{E}-01$ & 2.99E-02 & $8.43 \mathrm{E}-03$ \\
\hline 1123 & 30 & 30 & $1.54 \mathrm{E}-04$ & $3.09 \mathrm{E}-04$ & $1.66 \mathrm{E}-01$ & 1.47E-01 & $3.11 \mathrm{E}-02$ & 8.77E-03 \\
\hline 1152 & 30 & 30 & $1.54 \mathrm{E}-04$ & $3.09 \mathrm{E}-04$ & $1.69 \mathrm{E}-01$ & $1.50 \mathrm{E}-01$ & $3.23 \mathrm{E}-02$ & $9.11 \mathrm{E}-03$ \\
\hline 1181 & 30 & 30 & $1.54 \mathrm{E}-04$ & $3.09 \mathrm{E}-04$ & $1.72 \mathrm{E}-01$ & $1.53 \mathrm{E}-01$ & 3.35E-02 & $9.46 \mathrm{E}-03$ \\
\hline 1210 & 30 & 30 & $1.54 \mathrm{E}-04$ & 3.09E-04 & $1.75 \mathrm{E}-01$ & $1.56 \mathrm{E}-01$ & $3.48 \mathrm{E}-02$ & $9.81 \mathrm{E}-03$ \\
\hline 1238 & 30 & 30 & $1.54 \mathrm{E}-04$ & $3.09 \mathrm{E}-04$ & $1.78 \mathrm{E}-01$ & $1.59 \mathrm{E}-01$ & 3.60E-02 & $1.02 \mathrm{E}-02$ \\
\hline 1267 & 30 & 30 & $1.54 \mathrm{E}-04$ & $3.09 \mathrm{E}-04$ & $1.80 \mathrm{E}-01$ & $1.62 \mathrm{E}-01$ & $3.73 \mathrm{E}-02$ & $1.05 \mathrm{E}-02$ \\
\hline 1296 & 30 & 30 & $1.54 \mathrm{E}-04$ & $3.09 E-04$ & 1.83E-01 & 1.65E-01 & 3.86E-02 & 1.09E-02 \\
\hline 1325 & 30 & 30 & 1.54E-04 & $3.09 \mathrm{E}-04$ & $1.86 \mathrm{E}-01$ & 1.68E-01 & 3.99E-02 & 1.13E-02 \\
\hline 1354 & 30 & 30 & $1.54 \mathrm{E}-04$ & $3.09 \mathrm{E}-04$ & $1.89 \mathrm{E}-01$ & $1.71 \mathrm{E}-01$ & $4.12 \mathrm{E}-02$ & 1.16E-02 \\
\hline 1382 & 30 & 30 & $1.54 \mathrm{E}-04$ & $3.09 \mathrm{E}-04$ & $1.92 \mathrm{E}-01$ & $1.74 \mathrm{E}-01$ & 4.25E-02 & 1.20E-02 \\
\hline 1411 & 30 & 30 & $1.54 \mathrm{E}-04$ & $3.09 \mathrm{E}-04$ & $1.94 \mathrm{E}-01$ & 1.77E-01 & 4.39E-02 & 1.24E-02 \\
\hline 1440 & 30 & 30 & $1.54 \mathrm{E}-04$ & $3.09 E-04$ & 1.97E-01 & 1.79E-01 & 4.52E-02 & 1.28E-02 \\
\hline
\end{tabular}


$\underline{\text { Distribution for ANL-02-31 }}$

Internal (Printed and Electronic Copies):
S. B. Aase
M. L. Dietz
C. Pereira
H. A. Arafat (5)
E. Freiberg
M. C. Regalbuto
A. J. Bakel
A. V. Guelis
G. F. Vandegrift
D. B. Chamberlain
J. E. Helt
Y. I. Chang
R. A. Leonard
V. A. Davis
K. L. Nash
S. K. Zussman

Internal (Electronic Copy Only):
D. L. Bowers
E. C. Gay
E. Sackett, Library-W
M. A. Buckley, Library-E
M. R. Hale, TIS
J. Sedlet
Library
D. Lewis
R. J. Finch
C. J. Mertz
M. J. Steindler
TIS Files

\section{External (Printed and Electronic Copies):}

Chemical Technology Division Review Committee Members:

H. U. Anderson, University of Missouri-Rolla, Rolla, MO

R. A. Greenkorn, Purdue University, West Lafayette, IN

C. L. Hussey, University of Mississippi, University, MS

M. V. Koch, University of Washington, Seattle, WA

V. P. Roan, Jr., University of Florida, Gainesville, FL

J. R. Selman, Illinois Institute of Technology, Chicago, IL

J. S. Tulenko, University of Florida, Gainesville, FL

J. F. Birdwell, Oak Ridge National Laboratory, Oak Ridge, TN

P. V. Bonnesen, Oak Ridge National Laboratory, Oak Ridge, TN

S. G. Campbell, Westinghouse Savannah River Company, Aiken, SC

J. T. Carter, Westinghouse Savannah River Company, Aiken, SC

S. Clifford, Westinghouse Savannah River Company, Aiken, SC

L. H. Delmau, Oak Ridge National Laboratory, Oak Ridge, TN

H. D. Harmon, Westinghouse Savannah River Company, Aiken, SC

R. T. Jubin, Oak Ridge National Laboratory, Oak Ridge, TN

J. D. Law, Idaho National Engineering and Environmental Laboratory, Idaho Falls, ID

R. Leugemors, Pacific Northwest National Laboratory, Richland, WA

G. J. Lumetta, Battelle, Pacific Northwest National Laboratory, Richland, WA

M. Maxted-Miles, DOE-SR, Aiken, SC

B. A. Moyer, Oak Ridge National Laboratory, Oak Ridge, TN

M. Norato, Westinghouse Savannah River Company, Aiken, SC

R. A. Pierce, Westinghouse Savannah River Company, Aiken, SC

P. C. Suggs, DOE-SR, Aiken, SC

M. C. Thompson, Westinghouse Savannah River Company, Aiken, SC

T. A. Todd, Idaho National Engineering and Environmental Laboratory, Idaho Falls, ID 
D. D. Walker, Westinghouse Savannah River Company, Aiken, SC

V. Wheeler, DOE-SR, Aiken, SC

External (Printed Copy Only):

C. Conner, BWX Technologies, Inc., Lynchburg, VA

K. D. Gerdes, DOE-EM, Tanks Focus Area Headquarters, Germantown, MD

T. P. Pietrok, USDOE, Richland Operations Office, Richland, WA

B. J. Williams, Pacific Northwest National Laboratory, Tanks Focus Area Technical Team, Richland, WA

External (Electronic Copy Only):

W. D. Clark, DOE-SR, Aiken, SC

S. M. Dinehart, Los Alamos National Laboratory, Los Alamos, NM

R. E. Edwards, Westinghouse Savannah River Company, Aiken, SC

S. D. Fink, Westinghouse Savannah River Company, Aiken, SC

D. Hobbs, Westinghouse Savannah River Company, Aiken, SC

L. N. Klatt, Oak Ridge National Laboratory, Oak Ridge, TN

D. E. Kurath, Pacific Northwest National Laboratory, Richland, WA

K. T. Lang, USDOE, Washington, DC

J. W. McCullough, USDOE, Aiken, SC

C. P. McGinnis, Oak Ridge National Laboratory, Oak Ridge, TN

A. L. Olson, Idaho National Engineering and Environmental Laboratory, Idaho Falls, ID

M. J. Palmer, Los Alamos National Laboratory, Los Alamos, NM

L. M. Papouchado, Westinghouse Savannah River Company, Aiken, SC

R. A. Peterson, Bechtel-Washington Process Technology, Richland, WA

B. M. Rapko, Pacific Northwest National Laboratory, Richland, WA

R. D. Rogers, University of Alabama, Department of Chemistry, Tuscaloosa, AL

K. J. Rueter, Bechtel-Washington Process Technology, Richland, WA

P. Rutland, Bechtel-Washington Process Technology, Richland, WA

S. Schlahta, Pacific Northwest National Laboratory, Richland, WA

J. L. Swanson, Richland, WA

W. L. Tamosaitis, Westinghouse Savannah River Company, Aiken, SC

L. L. Tavlarides, Syracuse University, Syracuse, NY

D. W. Tedder, Georgia Institute of Technology, Atlanta, GA

V. Van Brunt, University of South Carolina, Columbia, SC

J. F. Walker, Oak Ridge National Laboratory, Oak Ridge, TN

J. S. Watson, Oak Ridge National Laboratory, Oak Ridge, TN

R. M. Wham, Oak Ridge National Laboratory, Oak Ridge, TN

W. R. Wilmarth, Westinghouse Savannah River Company, Aiken, SC 